OPEN ACCESS

Edited by:

Anish Thomas,

National Cancer Institute (NCl),

United States

Reviewed by:

Lucia Anna Muscarella,

Casa Sollievo della Sofferenza

(IRCCS), Italy

Andrea Camerini,

Ospedale Versilia, Azienda Us

Toscana nord ovest, Italy

*Correspondence:

Emilio Bria

emilio.bria@unicatt.it

${ }^{\dagger}$ These authors share last authorship

Specialty section:

This article was submitted to

Thoracic Oncology,

a section of the journal

Frontiers in Oncology

Received: 06 January 2021 Accepted: 17 March 2021

Published: 15 April 2021

Citation:

Ferrara MG, Stefani A, Simbolo M, Pilotto S, Martini M, Lococo F, Vita E,

Chiappetta M, Cancellieri $A$

D’Argento E, Trisolini R, Rindi G,

Scarpa A, Margaritora S, Milella M, Tortora G and Bria E (2021) Large Cell

Neuro-Endocrine Carcinoma of the

Lung: Current Treatment Options and

Potential Future Opportunities.

Front. Oncol. 11:650293.

doi: 10.3389/fonc.2021.650293

\section{Large Cell Neuro-Endocrine Carcinoma of the Lung: Current Treatment Options and Potential Future Opportunities}

Miriam Grazia Ferrara ${ }^{1,2}$, Alessio Stefani ${ }^{1,2}$, Michele Simbolo ${ }^{3}$, Sara Pilotto ${ }^{4}$, Maurizio Martini ${ }^{5}$, Filippo Lococo ${ }^{6}$, Emanuele Vita ${ }^{1,2}$, Marco Chiappetta $^{6}$, Alessandra Cancellieri ${ }^{5}$, Ettore D'Argento ${ }^{1,2}$, Rocco Trisolini $^{7}$, Guido Rindi ${ }^{5}$, Aldo Scarpa $^{3}$, Stefano Margaritora ${ }^{6}$, Michele Milella ${ }^{4}$, Giampaolo Tortora ${ }^{1,2+}$ and Emilio Bria ${ }^{1,2 * t}$

${ }^{1}$ Comprehensive Cancer Center, Fondazione Policlinico Universitario Agostino Gemelli IRCCS, Roma, Italy, ${ }^{2}$ Medical Oncology, Università Cattolica del Sacro Cuore, Roma, Italy, ${ }^{3}$ Department of Diagnostics and Public Health, Section of Anatomic Pathology, University of Verona, Verona, Italy, ${ }^{4}$ Section of Oncology, Department of Medicine, University of Verona Hospital Trust, Verona, Italy, ${ }^{5}$ Institute of Pathology, Università Cattolica Del Sacro Cuore, Fondazione Policlinico Universitario Agostino Gemelli IRCCS, Roma, Italy, ${ }^{6}$ Thoracic Surgery, Fondazione Policlinico Universitario Agostino Gemelli IRCCS, Università Cattolica del Sacro Cuore, Rome, Italy, 7 Interventional Pulmonology Unit, Fondazione Policlinico Universitario Agostino Gemelli IRCCS, Università Cattolica del Sacro Cuore, Rome, Italy

Large-cell neuroendocrine carcinomas of the lung (LCNECs) are rare tumors representing $1-3 \%$ of all primary lung cancers. Patients with LCNEC are predominantly male, older, and heavy smokers. Histologically, these tumors are characterized by large cells with abundant cytoplasm, high mitotic rate, and neuroendocrine immunohistochemistrydetected markers (chromogranin-A, synaptophysin, and CD56). In 2015 the World Health Organization classified LCNEC as a distinct subtype of pulmonary large-cell carcinoma and, therefore, as a subtype of non-small cell lung carcinoma (NSCLC). Because of the small-sized tissue samples and the likeness to other neuroendocrine tumors, the histological diagnosis of LCNEC remains difficult. Clinically, the prognosis of metastatic LCNECs is poor, with high rates of recurrence after surgery alone and overall survival of approximately $35 \%$ at 5 years, even for patients with early stage disease that is dramatically shorter compared with other NSCLC subtypes. First-line treatment options have been largely discussed but with limited data based on phase II studies with small sample sizes, and there are no second-line well defined treatments. To date, no standard treatment regimen has been developed, and how to treat LCNEC is still on debate. In the immunotherapy and targeted therapy era, in which NSCLC treatment strategies have been radically reshaped, a few data are available regarding these opportunities in LCNEC. Due to lack of knowledge in this field, many efforts have been done for a deeper understanding of the biological and molecular characteristics of LCNEC. Next generation sequencing analyses have identified subtypes of LCNEC that may be relevant for prognosis and response to therapy, but further studies are needed to better define the clinical impact of these results. Moreover, scarce data exist about 
PD-L1 expression in LCNEC and its predictive value in this histotype with regard to immunotherapy efficacy. In the literature some cases are reported concerning LCNEC metastatic patients carrying driver mutations, especially EGFR alterations, showing targeted therapy efficacy in this setting of disease. Due to the rarity and the challenging understanding of LCNEC, in this review we aim to summarize the management options currently available for treatment of LCNEC.

Keywords: large cell, lung cancer, review, neuro-endocrine, treatment

\section{INTRODUCTION}

Large cell neuroendocrine carcinoma of the lung (L-LCNEC) represents a rare but highly aggressive NSCLC with neuroendocrine differentiation, accounting for $2-3 \%$ of all lung cancers. Patients are often male and older with heavy smoking history. In 2015, the World Health Organization classified LCNEC as a distinct subtype of pulmonary large-cell carcinoma and, therefore, as a neuroendocrine non-small cell lung carcinoma (NSCLC) (1-4). Histologically, LCNEC has a neuroendocrine morphology including organoid or trabecular patterns, rosette-like structures, or peripheral palisading. Tumor cells exhibit abundant (often eosinophilic) cytoplasm, prominent nucleoli, large areas of necrosis, and high mitotic rate. Radiologically, LCNEC can be solitary or multiple and is often localized in the lung periphery (5-7). Clinically, LCNEC frequently spreads metastases to the liver, brain and/or bone. The prognosis of patients with LCNEC is poor, and stage by stage, survival curves of L-LCNEC and SCLC almost overlap, with high rates of recurrence even for patients with early stage disease and overall survival dramatically shorter compared with other NSCLC subtypes $(8,9)$. Regarding all stages, 5-year survival rate and 5-year disease-free survival rate are about 35 and $27 \%$ respectively; great part of relapses occurred within the first 2-year follow-up $(10,11)$. Treatment strategies for this tumor are largely discussed, and to date, no standard management exists, especially for advanced stages due to its rarity resulting in a scarce accrual in clinical trials. Resectable LCNEC is treated by surgical excision; for unresectable LCNEC with locally advanced or metastatic disease optimal systemic treatment has not been established, and it is largely discussed since patients may be treated with SCLC-regimen (etoposide/ platinum) or NSCLC regimen according to the American Society of Clinical Oncology (ASCO) guidelines (12). Nevertheless, LCNEC appears overall more aggressive than most NSCLC and less responsive to SCLC-regimens $(13,14)$. With regard to the tricky treatment choice, recent data suggest that RB1 expression could represent a potential biomarker to select the best treatment for LCNEC patients (RB1 loss should guide toward SCLC-chemotherapy; on the other hand, LCNEC showing intact RB1 expression should be treated with NSCLCregimens) $(15,16)$. No standard second-line treatment exists, and a few data are available regarding patients treated with checkpoint inhibitors after first-line progression, with a moderate efficacy reported (17).
Based on the difficult classification of LCNEC, several efforts have been done for a deeper understanding of its molecular characteristics. Thereby some studies have detected some subtypes of LCNEC are more sensitive to chemotherapy, the existence of potential targetable gene mutations and the presence of transcriptomic subtypes with specific genomic alterations that correlate with prognosis $(15,18)$.

In the last decade, targeted therapy for 'oncogene addicted' disease and immunotherapy for PD-L1 positive patients have deeply reshaped treatment strategies in NSCLC. Instead, for rare tumors as LCNECs, clinical trials are difficult to conduct, and to date, there is not a clear indication for immunotherapy or targeted therapy in LCNEC patients. Only a few studies in literature report patients treated with immunotherapy, mainly pretreated patients, showing a higher percentage of PD-L1 expression in comparison to other neuroendocrine tumors (especially SCLC) and a moderate efficacy of checkpoint inhibitors (19, 20). Regarding 'oncogene addiction' in LCNEC, some cases are reported in 'pure' LCNEC (without adenocarcinoma component) metastatic patients carrying driver mutations, including EGFR alterations (21, 22), ALK rearrangements (23), and KRAS mutations $(24,25)$. Although infrequent, the driver mutations reported in LCNEC draw a sharp contradistinction with classic SCLC, which in the 'pure' form is consistently devoid of adenocarcinoma-type driver mutations $(26,27)$.

Considering the above discussion, there is an emerging need for an agreement on the best management to adopt for this aggressive lung cancer histotype. The aim of this review is to point out the current clinical and molecular findings and to highlight the potential treatment strategies for LCNEC patients.

\section{HISTO-PATHOLOGICAL FEATURES}

Histologically, LCNEC diagnosis may be challenging. Any amount of morphologically recognizable adenocarcinoma, squamous cell carcinoma, giant cell carcinoma, or spindle cell carcinoma in combination with LCNEC is sufficient for the diagnosis of combined LCNEC with the corresponding component (28). Neuroendocrine markers (synaptophysin, chromogranin A or CD56) are typically present and are diriment for diagnosis, although they are not specific of LCNEC and may be observed in other neuroendocrine tumors. Indeed, the differentiation of LCNEC from small cell lung carcinoma (SCLC) or atypical carcinoid can be 
challenging, especially in small biopsy sample specimens (29). For an accurate diagnosis, LCNEC requires the presence of neuroendocrine features identified using light microscopy, neuroendocrine differentiation confirmed by electron microscopy and/or immunohistochemistry (synaptophysin, chromogranin A or CD56 positivity), mitoses $\geq 11$ per $2 \mathrm{~mm}^{2}$, and non-small cell cytomorphology with abundant eosinophilic cytoplasm and prominent nucleoli (30). By immunohistochemistry (IHC), LCNEC is positive for chromogranin and CD56 in greater than $80 \%$ of cases, and synaptophysin and TTF- 1 in approximately 40 to $50 \%$ of cases (31). Because of the difficult diagnosis in biopsies or cytology specimens, LCNEC may be suspected when the tumor shows non-small cells, high-grade neuroendocrine features with no overt squamous or glandular differentiation and expresses more than one neuroendocrine marker (synaptophysin, chromogranin, and/or CD56) (16). Considering the above discussion, distinguishing LCNEC from SCLC represents the most insidious challenge due to the similar neuroendocrine morphology and biomarkers' expression. Because complete loss of RB1 expression is found in greater than $95 \%$ of SCLCs and approximately $50 \%$ of LCNECs, intact RB1 expression in equivocal cases may favor LCNECs over SCLCs $(25,32)$. Recently, a new category of thoracic tumors has been described, designated as SMARCA4deficient undifferentiated thoracic tumor (SD-UTT) (33-35). Histologically, these tumors appear undifferentiated and show high-grade cell with rhabdoid morphology and synaptophysin immunoreactivity in $70 \%$ of cases (36). SD-UTTs do not present neuroendocrine features but are frequently characterized by high mitotic rate and extensive necrosis. Thus, in a crushed biopsy, these tumors may mimic LCNEC laying a pitfall for a correct diagnosis (28).

\section{MOLECULAR CHARACTERISTICS OF LCNEC}

Despite the remarkable advances in understanding the molecular landscape of lung adenocarcinoma, to date LCNEC has remained poorly characterized due to its low prevalence. Nevertheless, considering its aggressive features, a series of studies have been conducted to investigate the molecular characteristics of LCNEC. Rekhtman et al. (25), through next-generation sequencing, have shown that these tumors are molecularly heterogeneous and can be classified into two major subsets: small cell-like LCNEC (SCLC-like LCNEC) and non-small cell-like LCNEC (NSCLClike LCNEC). SCLC-like LCNEC subset was characterized primarily by RB1 and TP53 inactivation, whereas NSCLC-like LCNEC subset was associated with KRAS, serine/threonine kinase 11 gene (STK11)/kelch-like ECH associated protein 1 gene (KEAP1) mutations alone or concurrently with TP53 mutations. Additional less common molecular alterations seen almost exclusively in the SCLC-like LCNEC included PTEN mutations and MYCL1 amplification, and those seen exclusively in the NSCLC-like LCNEC involved MAP2K1, ERBB2, BRAF, and CDKN2A genes. Furthermore, a small subset of carcinoid-like LCNECs was identified, which was characterized by MEN1 alterations and lack of RB1/TP53 alterations. With regard to morphologic features, as expected, SCLC-like LCNEC subset tends to have a spectrum of characteristics closer to SCLC than NSCLC-like LCNEC subset, for example higher Ki-67 rates and smaller cell size (25).

A study in 75 LCNECs conducted by George et al. (37) has confirmed the existence of two LCNEC subtypes, one (type II) characterized by the concurrent inactivation of TP53 and RB1 (42\%) and one (type I) with TP53 and STK11/KEAP1 alterations (37\%) (Table 1).

Particular attention was paid to delta-like ligand 3 (DLL3) that is an inhibitory Notch-ligand highly expressed in SCLC and LCNEC $(38,39)$. It represents a new potential therapeutic target, and it has recently been reported that DLL3 mRNA expression is particularly upregulated in the LCNEC subgroup with STK11/ KEAP1 and TP53 co-mutations, in contrast to lower expression levels in RB1 and TP53 co-mutated LCNEC. Indeed, two gene expression profiles have been found: a DLL $3^{\text {high }} /$ Notch $^{\text {low }}$ profile with high expression levels of neuroendocrine genes (synaptophysin, chromogranin A) in LCNEC with TP53 and STK11/KEAP1 mutations and, on the other hand, a DLL $3^{\text {low }}$ / Notch $^{\text {high }}$ gene expression profile and lower expression levels of neuroendocrine genes in LCNEC with TP53 and RB1 mutations. The high percentage of DLL3 positive SCLC and LCNEC combined with low or non-detectable DLL3 levels in healthy tissue make DLL3 attractive for targeted therapy (40).

Considering the evidence that high-grade neuroendocrine carcinomas may evolve from preexisting carcinoids (41), Simbolo et al. have investigated the transcriptomic relationship between atypical carcinoids (ACs) and LCNECs and have demonstrated that ACs and LCNECs comprise three different molecular diseases of potential clinical relevance: one

TABLE 1 | Differences between LCNEC and SCLC.

\begin{tabular}{|c|c|c|}
\hline Characteristics & LCNEC & SCLC \\
\hline Incidence & $2-3 \%$ & $15-20 \%$ \\
\hline $\begin{array}{l}\text { Clinical } \\
\text { characteristics }\end{array}$ & Male, elderly, smokers & Male, elderly, smokers \\
\hline Site of disease & Mostly peripheral & Central \\
\hline Histological & Large cells & Small cells \\
\hline characteristics & $\begin{array}{l}\text { Abundant cytoplasm } \\
\text { Prominent nucleoli } \\
\text { Abundant necrosis }\end{array}$ & $\begin{array}{l}\text { Scarce cytoplasm } \\
\text { No prominent nucleoli } \\
\text { Abundant necrosis }\end{array}$ \\
\hline $\begin{array}{l}\text { IHC markers } \\
\text { positivity }\end{array}$ & $\begin{array}{c}\text { Synaptophysin, } \\
\text { Chromogranin A and/or } \\
\text { CD56 }\end{array}$ & $\begin{array}{l}\text { Synaptophysin, Chromogranin } \\
\text { A and/or CD56 }\end{array}$ \\
\hline $\begin{array}{l}\text { Molecular } \\
\text { subtypes }\end{array}$ & $\begin{array}{l}\text { SCLC-like (RB1 and TP53 } \\
\text { inactivation) } \\
\text { NSCLC-like (STK11, KEAP1 } \\
\text { and/or TP53 mutations) }\end{array}$ & RB1 and TP53 inactivation \\
\hline $\begin{array}{l}\text { Early stage } \\
\text { treatment }\end{array}$ & $\begin{array}{c}\text { Surgery and adjuvant } \\
\text { chemotherapy }\end{array}$ & Chemo-radiotherapy \\
\hline $\begin{array}{l}\text { Advanced stage } \\
\text { treatment }\end{array}$ & $\begin{array}{l}\text { Not established (mainly } \\
\text { platinum-etoposide) }\end{array}$ & $\begin{array}{l}\text { Platinum-etoposide plus } \\
\text { immunotherapy combination }\end{array}$ \\
\hline $\begin{array}{l}\text { Five-year } \\
\text { survival }\end{array}$ & $35 \%$ & $<15 \%$ \\
\hline
\end{tabular}

LCNEC, large cell neuroendocrine carcinoma; SCLC, small cell neuroendocrine carcinoma; NSCLC, non-small cell lung cancer; IHC, immunohistochemistry. 
AC-enriched group (C3) in which MEN1 inactivation plays a major role, one LCNEC-enriched group (C1) whose hallmark is $\mathrm{RB} 1$ inactivation, and one group (C2) with intermediate molecular features. These data support a progression of malignancy that may be traced by using combined molecular and immunohistochemical analysis (18). Regarding transcriptional profile, genes involved in the mitotic spindle and MYC targets were enriched in $\mathrm{C} 1$, consistent with recurrent MYC copy gain found in this cluster (18).

Another study has highlighted that the differences between carcinoids and high-grade carcinomas (LCNEC and SCLC) reside in the prevalence rates of the most frequently mutated genes (inactivating alterations of TP53 and RB1 were enriched in carcinomas, whereas MEN1 alterations were almost exclusive to carcinoids), with the exception of SMARCA2 which results in alteration in the LCNEC only.

Actually, the same gene alterations have been found in LCNEC and in low-grade tumors with a lower prevalence rate, suggesting the existence of a progression of malignancy from carcinoids to high-grade neuroendocrine carcinomas. Moreover, in this study, PI3K/AKT/mTOR pathway alterations have been identified in LCNEC, in particular PIK3CA mutations (11\%), PIK3CA copy number variation (CNV) (33.3\%), and RICTOR CNV (37\%). At last, survival analysis has shown that mutations of RB1 and copy gain of telomerase reverse transcriptase gene (TERT) are independent predictors of poor prognosis in patients with neuroendocrine tumor (regardless of subtype). These data underlie the relevance of molecular profiling in neuroendocrine tumors and, in particular, in LCNEC patients, to provide better diagnostic classification and prognostic stratification that could be helpful for their clinical management (42).

Derks et al. have evaluated whether the two LCNEC subtypes previously identified (RB1 mutated versus $\mathrm{RB} 1$ wild-type) have a predictive value on chemotherapy outcome. They have assessed that LCNEC patients carrying a wild-type RB1 gene or expressing the $\mathrm{RB} 1$ protein benefit more from platinum-based chemotherapy plus gemcitabine or taxane treatment than from standard SCLC chemotherapy (platinum plus etoposide) (15). This result confirms that molecular alterations may guide the best treatment strategy for these patients. With regard to the therapeutic implications for LCNEC subtypes, a recent study has demonstrated that patients with SCLC-like LCNEC had a shorter OS than those with NSCLC-like LCNEC despite higher response rate $(\mathrm{RR})$ to chemotherapy. Furthermore, treatment with etoposide-platinum was associated with superior response and survival in SCLC-like LCNEC compared to pemetrexed-platinum and gemcitabine/taxane-platinum doublets, while treatment with gemcitabine/taxane-platinum led to a shorter survival compared to etoposide-platinum or pemetrexed-platinum in NSCLC-like LCNEC patients. In summary, this study has stressed the concept that genomic subtyping has a potential role in prognosis prediction and therapeutic decision for patients with LCNEC (43).

Miyoshi et al. have performed targeted capture sequencing of all the coding exons of 244 cancer-related genes on 78 LCNEC samples (including 10 LCNECs combined with NSCLC) and have compared genomic alterations with those of 141 SCLCs.
The authors have found a relatively high prevalence of inactivating mutations in TP53 (71\%) and RB1 (26\%), but the mutation frequency in RB1 was lower than that in SCLCs (40\%). Additionally, genetic alterations in the PI3K/AKT/mTOR pathway were detected in $15 \%$ of the LCNEC: PIK3CA $3 \%$, PTEN 4\%, AKT2 4\%, RICTOR 5\%, and mTOR 1\%. Other activating alterations were detected in KRAS (6\%), FGFR1 (5\%), KIT (4\%), ERBB2 (4\%), and EGFR (1\%). Although the frequency of each mutation is low, the overall rate is significant, suggesting that molecular profiling is warranted in LCNEC for potential targeted therapies (44).

Pelosi et al. have studied the role of E-cadherin/ $\beta$-catenin system dysregulation in pulmonary neuroendocrine tumors. They have shown that changes in E-cadherin/ $\beta$-catenin expression patterns are common in lung neuroendocrine tumors, with either subcellular redistribution and/or down-regulation and that the subcellular compartmentalization of $\beta$-catenin is profoundly altered in LCNEC. Moreover, E-cadherin/ $\beta$-catenin system alterations are able to induce the activation of epithelialmesenchymal transition (EMT) in a subset of LCNEC and SCLC (45-47).

Another field of interest concerns the epigenetic alterations that might be involved in LCNEC development. In particular, $\mathrm{Li}$ et al. have demonstrated that the progressive loss of histone $\mathrm{H} 4$ acetylation at lysine16 (H4KA16) and trimethylation at lysine 20 (H4KM20) from low to high grade lung neuroendocrine tumors reflects the degree of differentiation and proliferative activity (48). Also methylation patterns have inspired interest because of their correlation with gene expression in lung neuroendocrine cancers (49).

Despite the efforts made to deeply understand LCNEC molecular features, a great part of its complexity has yet to be explored. Several studies performed have allowed the identification LCNEC subtypes with different genomic profiles and potential targetable gene alterations. Some correlations have also been found between LCNEC subtypes and response to chemotherapy regimens, giving interesting suggestions regarding how to select the best treatment for LCNEC patients. Furthermore, the extensive genomic profiling has detected the existence of numerous molecular alterations that, taken together, are not uncommon and lays the foundations for further developing targeted therapy. All these findings underlie the relevance of performing an extensive genomic profile in LCNEC to facilitate patients' management in terms of both prognostic implications and treatment selection.

\section{EARLY STAGE: ROLE OF SURGERY AND RADIOTHERAPY}

Despite its similarities to SCLC, surgery represents the cornerstone of the treatment of localized $\operatorname{LCNEC}(13,50,51)$. The low prevalence of this subgroup of NSCLC limits the quality of available data; in fact this recommendation mostly derives from retrospective studies and case series. Despite the absence of 
strong evidence, patients with resectable LCNEC should undergo surgery as a primary treatment (52).

Surgery represents a positive independent prognostic factor for OS, as demonstrated by Cao et al. in a large retrospective study including 1,530 patients with all-stages LCNEC. In their analysis, better outcomes were associated with lobectomy/ bilobectomy (HR 0.357, $\mathrm{p}<0.001$ ) than with wedge resection/ segmentectomy (HR 0.526, $\mathrm{p}<0.001$ ) or with pneumonectomy (HR 0.491, p < 0.001) (53). Regarding the surgical extent, in the subgroup analysis of the retrospective study by Wakeam et al. sub-lobar resection for stage I LCNEC was, once again, correlated with worse OS than lobectomy (HR 1.40, p < 0.001) (54). Another large retrospective study from $\mathrm{Gu}$ et al. showed that surgery, when feasible, significantly and independently improved OS compared to a cohort of not surgically treated patients (adjusted with propensity score matching-PSMmethod); this was demonstrated for stages I-II $(p=0.000)$, for stage IIIA ( $p=0.001)$, and even for stage IIIB ( $p=0.017)$, although the high recurrence rate after surgery alone justifies the need for a multimodal treatment in all-stage LCNEC (55). Several smaller series are in line with the above-mentioned studies, as demonstrated by Girelli et al. (56), Lowczak et al. (57), and Zacharias et al. (58). The latter study also demonstrated a possible role for systematic mediastinal nodal dissection in improving outcomes in LCNEC, but this finding might be explained by a more accurate staging of the disease.

Eichhorn and colleagues analyzed clinical and immunohistochemical predictors of survival after surgery in a retrospective cohort of 57 patients: a poorer prognosis was associated with advanced stage and advanced nodal involvement; a negative trend was also associated with the expression of neuroendocrine immunohistochemical markers: the expression of CgA, CD56 or both was a predictor for a significantly worse relapse-free survival and, not significantly, for a worse OS (59).

The role of radiotherapy (RT) in LCNEC is still unclear due to conflicting evidence. In the large retrospective study by Raman et al., patients with stage I LCNEC $(n=3,371)$ were treated with surgery $(96 \%)$ or with stereotactic body radiation therapy (SBRT) (4\%); in a multivariate analysis, OS was better in patients undergoing surgery (5 y OS 50 versus $27 \%$, HR 0.7 ). In stage II and IIIA patients, definitive chemoradiation was associated with worse survival than surgery, although $40 \%$ of patients in the surgery cohort with stage IIIA underwent adjuvant chemotherapy and $14 \%$ induction chemotherapy (60). SBRT was again compared to surgery in patients with T1-2 N0 LCNEC in the retrospective analysis by Lo and colleagues: after adjusting the cohorts with PSM method, median OS was 34.6 months in the SBRT group and 57.2 months in the surgical group with corresponding 5 y OS of 25 versus $48 \%$ ( $\mathrm{P}<0.0001)(61)$.

Wegner et al. retrospectively compared patients with T1-2 N0 LCNEC not suitable for surgery treated with SBRT or conventional fractionated radiotherapy (CFRT), and the results favored SBRT (median OS of 34.7 versus 23.7 months; $\mathrm{p}=0.02$ ) (62). Gu and colleagues demonstrated that patients with stage IIII LCNEC not suitable for surgery achieved a better prognosis with the combination of definitive chemo-radiation than with chemotherapy alone $(\mathrm{p}=0.003)(55)$.

In the post-operative setting, two large retrospective trials (54, 63) showed that, for patients with early stage LCNEC, RT did not give additional benefit in OS. Jiang et al. reported a possible detrimental effect of RT I-III LCNEC in resected patients (median OS 27 versus 44 months with surgery alone), but a limitation of this study is the lack of information on the possible use of adjuvant chemotherapy (64). These findings, together with the recently presented results of LungART trial in NSCLC with $\mathrm{N} 2$ nodal involvement, underlined the need to be cautious in considering post-operative RT (65).

In conclusion, differently from SCLC, surgery represents the first option for resectable LCNEC; RT might be offered to ineligible patients, especially as a part of a multimodal treatment including chemotherapy.

\section{EARLY STAGE: ROLE OF ADJUVANT CHEMOTHERAPY}

The prognosis of LCNEC remains poor, compared to other histotypes of NSCLC, even after radical surgery, highlighting the importance of a multimodal approach particularly in the earliest stages (60). In a retrospective analysis, Iyoda et al. found that the 5-year OS of patients with completely resected stage I NSCLC was $54.5 \%$ for LCNEC and $89.3 \%$ for other histotypes $(\mathrm{p}=0.0012)(66)$. Other studies reported 5-year survival rates ranging as follows: stage I 33-62\%, stage II 18-75\%, stage III 8$45 \%$ (14). Tumor recurrences tend to develop early: $64 \%$ within 1 year after surgery, 91\% within 3 years (10). Adjuvant chemotherapy (AC) has been investigated with the aim to improve recurrence-free survival and OS.

The rarity of this histology of NSCLC makes it difficult to perform a prospective trial on patients with completely resected LCNEC. In fact, up to now, there is only a small single-arm prospective study which included only patients with LCNEC, designed by Iyoda and colleagues; this trial evaluated the efficacy of AC with cisplatin plus etoposide on fifteen patients who underwent lobectomy with lymph node dissection. The control group derived from retrospective data. The results were in favor of the adjuvant arm, with a 5 y OS of 88.9 versus $47.4 \%$ in the retrospective $\operatorname{arm}(\mathrm{p}=0.0252)(67)$. Another prospective trial including forty patients with resected high-grade NEC of the lung (both LCNEC and SCLC) showed a positive trend on survival given by a post-operative chemotherapy with the combination of cisplatin and irinotecan for 4 cycles (68). A recently published phase III trial in the same population of high grade NEC of the lung was designed to show the superiority of cisplatin plus irinotecan over cisplatin plus etoposide as adjuvant regimen; the trial was interrupted at the second interim analysis due to futility; in fact no statistically significant difference was found between the two arms: at a median follow-up of 24.1 months, the 3-year relapse-free survival was $65.4 \%$ for etoposide plus cisplatin and $69 \%$ for irinotecan plus cisplatin (HR 1.076, $\mathrm{p}=$ 0.619) (69). 
Wakeam and colleagues, in a retrospective study with a cohort of 1,770 patients with LCNEC, showed that AC was associated with better OS especially if tumor dimension was greater than $3 \mathrm{~cm}$ (5 y OS 59.8 versus $42.1 \%$ ) and if chemotherapy was administered within 3-6 months after surgery; on the contrary, no advantages were seen if tumor was smaller than $2 \mathrm{~cm}$ and if chemotherapy was started after 6 months from surgery (54). In the retrospective analysis by Raman et al. 2,642 patients with stage I LCNEC were included in order to investigate AC in early stages: although a significant increase in OS was observed in the overall population ( $\mathrm{p}=$ 0.002), the subgroup analysis showed no survival benefit for patients with stage IA (63). Conversely, the retrospective study by Kujtan and colleagues conducted on 1,232 patients with stage I LCNEC showed that AC conferred a significant benefit in OS both in stage IA (HR 0.64, p = 0.006) and in stage IB (HR 0.43, $\mathrm{p}<0.001)(70)$.

A positive trend of AC in stage I LCNEC was confirmed by Veronesi et al. (71); Rossi et al. also demonstrated how SCLCtype adjuvant chemotherapy (platinum plus etoposide) was associated with better outcomes than NSCLC-type regimens (platinum plus taxane/vinorelbine/gemcitabine), with a median OS (mOS) of 42 versus 11 months $(\mathrm{p}<0.001)(72)$.

$\mathrm{Gu}$ and colleagues analyzed a cohort of 2,594 patients with all stages LCNEC who underwent different treatment modalities; not only the benefit of adjuvant chemotherapy was observed from stage I to stage III, but also the combination of surgery and chemotherapy represented the best strategy for these patients compared to surgery plus radiotherapy or surgery plus chemoradiation (55). Sarkaria et al. confirmed a positive effect of AC and possibly, of neo-adjuvant chemotherapy, in patients from stages IB to IIIA (73).

In conclusion, although these studies showed a positive impact on survival by $\mathrm{AC}$, no general recommendation can be made due to the retrospective nature of most of the data and, most importantly, due to the lack of information on the regimens used (Table 2).

\section{LOCALLY-ADVANCED DISEASE}

Patients with unresectable stage III LCNEC should receive, in accordance with the latest guidelines, a multimodal treatment comprising systemic chemotherapy and radiotherapy (52). As already mentioned for the early stage, most recommendations derive from retrospective data and from the translation of results of studies conducted on SCLC and NSCLC patients.

Limmonik et al. have recently published the results of a large retrospective trial of 5,797 patients with locally advanced LCNEC in which they compared the use of definitive chemo-radiotherapy (CRT) versus chemotherapy alone. Despite the limitations of the study due to the retrospective nature and the lack of information about the regimen of chemotherapy administrated, the results were in favor of CRT with a mOS of 16.1 versus 11.9 months in the chemotherapy group ( $\mathrm{p}<0.0001)(74)$.

These results were confirmed in the retrospective study conducted by $\mathrm{Gu}$ and colleagues: the subgroup of LCNEC patients not suitable for surgery had better outcomes with the combination of definitive CRT than with chemotherapy alone $(\mathrm{p}=0.003)$; nevertheless, this analysis included not only locally advanced LCNEC but also inoperable stage I and II patients (55).

Shimada et al. retrospectively evaluated a cohort of 25 patients with unresectable high-grade neuroendocrine carcinomas of the lung: those who underwent CRT had higher objective response rate (ORR) than those treated with chemotherapy alone (86 versus 61\%), but the sample size was too small to draw any conclusion (75).

With regard to the regimen choice, no prospective data are available. Large clinical trials conducted for stage III NSCLC patients rarely included a very low proportion of LCNEC. In addition, the activity and efficacy of SCLC-like and NSCLC-like regimens have been better investigated in the metastatic setting, as discussed below. However, two small retrospective studies involving both locally advanced and metastatic LCNEC showed that platinum-based SCLC-like regimens could reach response rates similar to those of $\operatorname{SCLC}(75,76)$.

TABLE 2 | Available studies evaluating adjuvant chemotherapy in LCNEC.

\begin{tabular}{|c|c|c|c|c|}
\hline Authors & Study & Patients & Treatment & Outcomes \\
\hline lyoda et al. & Prospective (single arm) & 50 & Cisplatin-Etoposide & 5 y OS: $88.9 \%$ \\
\hline Kenmotsu et al. & Prospective (single arm) & 40 (23 LCNEC) & Cisplatin-Irinotecan $\times 4$ cycles & 3 y OS: $81 \%$ (86\% LCNEC) \\
\hline Kenmotsu et al. & Prospective (two arms) & 221 & Cisplatin-Irinotecan vs Cisplatin-Etoposide & 3 y RFS: 69 vs $65.4 \%(p=0.619)$ \\
\hline Wakeam et al. & Retrospective & 1770 & $S+A C(463) v s S$ & 5 y OS: 59.2 vs $45.3 \%$ \\
\hline Raman et al. & Retrospective & 2642 (stage I) & $S+A C(481)$ vs $S(2,161)$ & $\begin{array}{c}\text { mOS: } 81 \text { vs } 65 \text { m }(p=0.002) \\
\text { Stage IA HR } 0.92 \\
\text { Stage IB HR } 0.67\end{array}$ \\
\hline Kujtan et al. & Retrospective & 1232 (stage I) & $\mathrm{S}+\mathrm{AC}(275)$ vs S (957) & $\begin{array}{c}\text { 5y OS: } 64.5 \% \text { vs } 48.4 \%(\mathrm{p}<0.001) \\
\text { Stage IA HR } 0.63\left(^{\star}\right) \\
\text { Stage IB HR } 0.55\left(^{\star}\right)\end{array}$ \\
\hline Veronesi et al. & Retrospective & 144 & NAC or AC & 5 y OS: $42.5 \%$ \\
\hline Rossi et al. & Retrospective & 83 & SCLC-based AC vs NSCLC-based AC & mOS 42 vs 11 m (p=0.0001) \\
\hline Gu et al. & Retrospective & 2,594 (569 stage I) & $S$ vs $S+A C$ vs $S+R T$ vs $S+C R T$ & $S+$ AC best option $(p=0.03)$ \\
\hline Sarkaria et al & Retrospetive & 100 & NAC or AC (platinum-based) & mOS 7.4 vs 2 years \\
\hline
\end{tabular}

S, Surgery; AC, adjuvant chemotherapy; NAC, neoadjuvant chemotherapy; RFS, relapse free survival; mOS, median overall survival. *propensity-matched. 
In conclusion, considering the few available data, concurrent chemoradiation (CRT) with four cycles of platinum and etoposide could represent a potential appropriate treatment for stage III unresectable LCNEC (77).

\section{ADVANCED DISEASE: SYSTEMIC CHEMOTHERAPY}

Historically, data on systemic therapeutic approaches to stage IV LCNEC has been conflicting due to the likeness of this histotype to SCLC neuroendocrine features and, at the same time, the classification as NSCLC. The gold standard chemotherapy for advanced or metastatic LCNEC is still debated $(75,76,78-82)$, and due to the rarity of LCNEC subtype, there are no clinical trials tailored for LCNEC patients. Platinum compounds and taxanes have established activity in advanced disease $(76,78)$, but the prognosis remains poor with a median overall survival (OS) of $8-12$ months $(79,82)$. Thus, there is an imperative need for prospective studies of novel compounds. Nevertheless, considering LCNEC's biological relation to SCLC, four to six cycles of etoposide combined with cisplatin or carboplatin chemotherapy are generally recommended for the advanced stage $(2,10)$. Sun et al. retrospectively evaluated whether advanced LCNEC should be treated similarly to SCLC or NSCLC. Of 45 patients, 11 were treated with SCLC-regimens and 34 with NSCLC-standard chemotherapy. The median PFS was 6.1 versus 4.9 months $(\mathrm{p}=0.41)$, the median OS was 16.5 versus 9.2 months $(\mathrm{p}=0.10)$, and the ORR was 73 versus $50 \%$ $(\mathrm{p}=0.19)$ in the SCLC and NSCLC regimen groups, respectively. Even for second-line treatment the most common drugs used in SCLC (taxanes or irinotecan) showed a clear superiority to those used in NSCLC (pemetrexed, gefitinib or erlotinib) (78). Le Treut et al. conducted a phase II prospective study on 42 advanced LCNEC patients treated with cisplatin and etoposide doublets. The median PFS and median OS were 5.2 and 7.7 months, respectively (79). Igawa et al. evaluated the clinical efficacy of chemotherapy for unresectable LCNEC, showing that outcomes are comparable to that for SCLC extensive disease (80). Similarly, in the study of Yamazaki et al. twenty LCNEC patients were enrolled, of which nine received cisplatin and etoposide; six cisplatin, vindesine, and mitomycin; four cisplatin and vindesine; and one cisplatin alone. Patients treated with platinum doublets achieved an ORR comparable to that in SCLC (76). Shimada et al. retrospectively evaluated 25 LCNEC patients treated with chemotherapy or chemo-radiotherapy as first-line treatment and compared their data with those of 180 SCLC patients. The ORR was 86 and $98 \%$ in LCNEC and SCLC respectively; the 1-year survival rate of LCNEC was 34 versus $49 \%$ in SCLC patients ( $\mathrm{p}=$ 0.84 ). With regard to the efficacy of second-line chemotherapy, it appeared significantly lower for LCNEC (ORR of $17 \%$ in LCNEC patients versus $45 \%$ in SCLC patients) (75). In their study, Fujiwara et al. demonstrated some activity of irinotecan and paclitaxel with or without platinum in patients with LCNEC (median OS 10.3 months and 1-year survival rate 47.6\%) (81).
Niho et al. conducted a phase II study to evaluate irinotecan plus cisplatin combination in patients with advanced LCNEC; 30 patients with LCNECs and 10 with SCLCs were enrolled. The ORR and median OS was 40 versus $80 \%(\mathrm{p}=0.0823)$ and 12.6 versus 17.3 months $(\mathrm{p}=0.047)$ for LCNEC group and SCLC group, respectively. The authors conclude that this regimen was active in LCNEC, but ORR and OS were inferior to those of SCLC, showing a minor chemo-responsiveness of LCNEC (82). Rossi et al. (72) analyzed 83 cases of LCNEC, and regarding chemotherapy regimens, they showed a greater efficacy of platinum-etoposide chemotherapy in advanced stage with an ORR of $29 \%$, including two cases of complete responses (CR) and four partial responses (PR); on the other hand, no cases of $\mathrm{CR}$ or $\mathrm{PR}$ were reported in patients treated with different chemotherapy schedules. Tokito et al. (83) compared the efficacy of SCLC-regimens in LCNEC patients and in so called 'possible LCNEC'. The term 'possible LCNEC' was introduced by Travis et al. (84) referring to NSCLC with neuroendocrine IHC markers and neuroendocrine morphologic features on small samples derived from biopsies. They found no statistical differences in ORR, PFS, and OS between 'pure LCNEC' and 'possible LCNEC' groups. Considering the molecular subtypes of LCNEC (SCLC-like or NSCLC-like LCNEC) previously discussed, Rekhtman et al. demonstrated that most of patients with SCLC-like LCNEC responded to platinum-based regimens, while none of the patients with NSCLC-like LCNEC (25).

The greatest part of these studies does not show significant differences in the efficacy of SCLC-regimens in SCLC and LCNEC patients and, in clinical practice, a trend has been observed towards treating LCNEC patients in the same way as SCLC, rather than as NSCLC. Despite these results, Naidoo et al. assessed chemotherapy efficacy in 49 LCNEC patients, concluding that LCNEC may not respond to platinum/ etoposide as strongly as cases of extensive stage SCLC (14). Accordingly, Zhuo et al. (43) confirmed that the response rate to platinum/etoposide in SCLC-like LCNEC patients is lower than historically reported for conventional SCLC.

Certainly, the small sample size of these studies reduces their results' impact and underlies the heterogeneous biology of LCNEC, highlighting the emerging need of more extensive prospective clinical trials.

Some reports investigated the efficacy of other chemotherapic compounds; for example, pemetrexed efficacy in LCNEC was found to be very poor, may be due to higher levels of thymidylate synthase expressed by this histotype compared with other NSCLC subtypes $(85,86)$. In a prospective, multicenter, phase II trial chemotherapy-naïve advanced LCNEC, patients received everolimus in combination with paclitaxel and carboplatin for four cycles followed by maintenance everolimus until progression. The ORR was $45 \%$, the median PFS 4.4 months, and the median OS 9.9 months. This study showed that everolimus in combination with chemotherapy could be an effective first-line treatment for patients with metastatic LCNEC (87). In another study, the authors categorized firstline chemotherapy for LCNEC patients into three groups: group I, which comprised gemcitabine, docetaxel, paclitaxel, or 
vinorelbine; group II, with pemetrexed treatment; and group III, which comprised etoposide chemotherapy. In patients with LCNEC, the group I chemotherapy resulted in a longer OS than group II and group III chemotherapy (median OS 8.5, 5.9, and 6.7 months respectively) (88). Nedaplatin is a newer platinum derivative that, co-administered with irinotecan, demonstrated promising effectiveness and safety in a retrospective analysis of 18 chemo-naive patients with LCNEC (localized and advanced disease), but no prospective validation of this combination has been performed so far (89).

As for first-line treatment, also for second-line regimens there is not a standard of care for LCNEC patients. The most investigated drug in this setting is amrubicin, a fully synthetic topoisomerase II inhibitor, largely studied in SCLC patients (90). In a retrospective study, Yoshida et al. (91) reported the activity of amrubicin as single agent in second $(72 \%)$ or subsequent lines of therapy (28\%) in 18 LCNEC patients, showing ORR of $27.7 \%$, median PFS 3.1 months, and OS 5.1 months.

Considering the reported efficacy of temozolomide (TMZ) in neuroendocrine tumors (92), a case report in literature describes the administration of TMZ in a woman with stage IV pretreated LCNEC, achieving PR after five cycles of TMZ treatment (93).

Galvano et al. have evaluated the prognostic and the predictive roles of systemic inflammatory biomarkers in 120 SCLC and LCNEC patients: neutrophil-lymphocyte ratio (NLR), lactate dehydrogenase (LDH), advanced lung cancer inflammation index (ALI), and the Lung Immune Prognostic Index (LIPI) score. At the multivariate analysis, Eastern Cooperative Oncology Group performance status, LDH levels and response after first-line chemotherapy were independently associated with OS. Median OS for good, intermediate, and poor LIPI was 15,11 , and 9 months, respectively $(\mathrm{p}=0.091)$. Patients with higher NLR $(>1.93)$ had an increased probability of tumor progression $(p=0.045)$. This study has provided evidence that levels of NLR, LDH, and ALI evaluated at diagnosis showed a significant prognostic role in lung neuroendocrine carcinomas (NEC), while LIPI stratified patients into three prognostic groups: good, intermediate and poor. Thus, systemic inflammatory biomarkers could facilitate the understanding of survival differences in the clinical management of lung NEC patients (94).

Unfortunately, the major conclusion from the above studies is that patients with advanced LCNEC have extremely poor prognosis and that the conflicting studies results do not allow a full agreement regarding the best treatment to use. Despite cytotoxic effects that many times are translated into tumor response, chemotherapy offers modest OS benefit and remains far from changing the natural history of advanced LCNEC (Table 3).

\section{POTENTIAL FUTURE OPPORTUNITIES}

\section{Immunotherapy}

In the last decade, immunotherapy has dramatically changed the natural history of NSCLC improving OS and quality of life of these patients compared to standard chemotherapy (95).

TABLE 3 | Antineoplastic therapies in the first-line setting.

\begin{tabular}{|c|c|c|c|c|}
\hline Authors & Study & Patients & Treatment & Outcomes \\
\hline Sun et al. & Retrospective & 45 LCNEC & SCLC-based (11) vs NSCLC-based (34) & $\begin{array}{l}\text { mPFS } 6.1 \text { vs } 4.9 \text { m }(p=0.41) \\
\text { mOS } 16.5 \text { vs } 9.2 \text { m }(p=0.1)\end{array}$ \\
\hline Le Treut et al. & Prospective & 42 LCNEC & Cisplatin-Etoposide & $\begin{array}{c}\operatorname{mPFS} 5.2 \mathrm{~m} \\
\operatorname{mOS} 7.7 \mathrm{~m}\end{array}$ \\
\hline Igawa et al. & Retrospective & 14 LCNEC, 77 SCLC & $\begin{array}{l}\text { Platinum-based for SCLC; platinum and/or vinorelbine, } \\
\text { docetaxel or irinotecan for LCNEC }\end{array}$ & mOS $10 \mathrm{~m}$ in LCNEC and 12.3 in SCLC \\
\hline Yamazaki et al. & Retrospective & 20 LCNEC & Cisplatin-based & Similar to SCLC \\
\hline Shimada et al. & Retrospective & 25 LCNEC vs 180 SCLC & Platinum-based CT/CRT & $\begin{array}{l}\text { 1y OS } 34 \text { vs } 49 \% \\
\text { ORR } 61 \text { vs } 63 \%\end{array}$ \\
\hline Fujiwara et al. & Retrospective & 22 LCNEC & Platinum-based or paclitaxel & $\operatorname{mos} 10.3 \mathrm{~m}$ \\
\hline Niho et al. & Prospective & $\begin{array}{l}30 \text { LCNEC, } 10 \text { SCLC, } 1 \\
\text { NSCLC }\end{array}$ & Cisplatin-Irinotecan & $\begin{array}{l}\text { RR } 40 \% \text { for LCNEC and } 80 \% \text { for SCLC } \\
\text { mOS } 12.6 \mathrm{~m} \text { for LCNEC and } 17.3 \mathrm{~m} \text { for } \\
\text { SCLC }\end{array}$ \\
\hline Rossi et al. & Retrospective & 83 LCNEC & Platinum-Etoposide vs other regimens & $\begin{array}{l}\text { Best results with Platinum-Etoposide } \\
\text { [ORR 29\% (2 CR)] }\end{array}$ \\
\hline Tokito et al & Retrospetive & $\begin{array}{l}10 \text { "pure" LCNEC, } 24 \\
\text { "possible" LCNEC }\end{array}$ & Platinum-based & $\begin{array}{l}\text { No difference between possible and pure } \\
\text { LCNEC }\end{array}$ \\
\hline Naidoo et al & Retrospective & 49 LCNEC & 70\% Platinum-Etoposide & $\begin{array}{c}\text { ORR } 37 \% \text { for Platinum-Etoposide (worse } \\
\text { than SCLC) }\end{array}$ \\
\hline Christopoulos et al & Prospective & 49 LCNEC & $\begin{array}{l}\text { Carboplatin + Paclitaxel } \\
+ \text { Everolimus }\end{array}$ & $\begin{array}{c}\text { ORR } 45 \%, \text { DCR } 74 \% \\
\text { mPFS } 4.4 \mathrm{~m} \\
\text { mOS } 9.9 \mathrm{~m}\end{array}$ \\
\hline Derks et al & Retrospective & 128 LCNEC & $\begin{array}{c}\text { Gemcitabine, taxane or vinorelbine vs Pemetrexed vs } \\
\text { platinum-etoposide }\end{array}$ & $\begin{array}{l}\text { Gemcitabine, taxane or vinorelbine } \\
\text { seemed to have better results }\end{array}$ \\
\hline Yoshiyuki et al & Retrospective & 18 LCNEC & Nedaplatin + Irinotecan & mOS $12.3 \mathrm{~m}$ \\
\hline
\end{tabular}

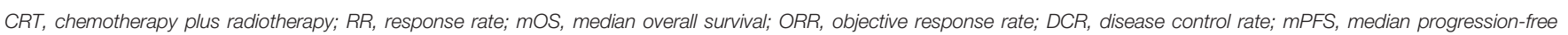
survival; $C R$, complete response. 
Recently, even for SCLC patients, immunotherapy (i.e., atezolizumab) has been approved for first-line treatment thanks to results deriving from IMpower133 trial (96); durvalumab, in combination with platinum-based chemotherapy, has also been approved in the same setting of disease due to CASPIAN trial results (97). The main targets of checkpoint inhibitors include programmed death-receptor 1 (PD-1), its ligand (PD-L1) and Cytotoxic T-Lymphocyte Antigen 4 (CTLA-4). The PD-L1 is located on the tumor cell surface, and its interaction with the $\mathrm{PD}-1$ receptor, expressed on activated T-cells, is known to suppress patient's immuneresponse mechanisms to the tumor $(98,99)$. Due to the rarity of LCNEC, clinical trials evaluating immunotherapy efficacy have mainly included patients with adenocarcinoma or squamous cell carcinoma. In contrast, very poor information about PD-L1 expression and checkpoint inhibitors efficacy is available for LCNEC, and no clinical trials have been conducted for these patients. About $60 \%$ of pulmonary LCNEC do not exhibit the SCLC molecular signature (TP53 and RB1 comutation) which might explain the large percentage of LCNEC patients who are platinum-refractory or rapidly progress on a platinum regimen $(25,37)$. Although prospective data regarding use of immune checkpoint in LCNEC is lacking, small studies have evaluated PD-L1 expression and frequency in LCNEC patients, supporting further exploration of immune checkpoint in these patients (17).

Fan et al. (19) studied PD-1 and PD-L1 expression in pulmonary neuroendocrine tumors; of 10 patients with LCNEC, $100 \%$ were PD-L1 positive, and $80 \%$ were PD- 1 positive. More recently, other studies analyzed PD-L1 expression, showing PD-L1 positivity in a minority of samples $(20,100)$. Kim et al. demonstrated that a substantial fraction of LCNEC (more than SCLC) has PD-L1 expression on tumorinfiltrating immune cells and that this expression is more frequently found in samples with higher mutation burden (101). The variability in percentages noted in these studies may be explained by the relatively small sample numbers of LCNEC cases employed. Nevertheless, comparing LCNEC with SCLC and low-grade neuroendocrine tumors, LCNEC exhibits a higher PD-L1 positivity, which is worth further investigations for potential immunotherapy application. Some studies were conducted to evaluate the correlation between PD-L1 expression and prognosis in patients with LCNEC. Eichhorn et al. (102) examined PD-L1 expression in 76 LCNEC patients, revealing that only $22 \%$ patients were positive for PD-L1 and, that positivity, was found on the tumor cell surface in $22 \%$ and within the tumor microenvironment (immune-cell infiltrate) in $36 \%$ of the patients. Furthermore, the authors demonstrated that PD-L1 expression has a prognostic role; indeed, poorer outcome was observed in patients with positive PD-L1 staining on the tumor cells and negative in the immune-cell infiltrate. On the contrary, negative tumors but a positive PD-L1 expression on immune-cell infiltrate was found to be connected with a better outcome (102). Hermans et al. investigated PD-L1 (scored positive if tumors showed $\geq 1 \%$ membranous staining) and CD8 expression (scored for intra-tumor T-cells and stromal cells) in advanced LCNEC, showing PD-L1 positivity in 16\% of tumor samples. In contrast with the previous study, PD-L1 positivity and stromal/intra-tumor CD8 were correlated with superior OS (103). Similar results come from Tsuruoka et al. and Inamura et al. $(20,104)$ that showed better outcome in LCNEC patients with positive expression of PD-L1. In another multicenter retrospective study, respectively 11 and $75 \%$ of the tumor samples expressed PD-L1 on tumor (TCs) and immune cells (ICs), thus IC+TC- was the most frequent co-expression pattern. Median OS of metastatic LCNEC patients with the IC-TC+ profile was shorter than for those with the IC+TCpattern, confirming Eichhorn results (105). Looking at these conflicting findings, it remains unclear whether PD-L1 could predict a good outcome in patients with LCNEC. Based on this background information, Ohtaki et al. performed a study to evaluate the relationship between outcome and expression of PD-L1, CD8, CD4, and Forkhead box protein P3 (Foxp3) in surgically resected LCNEC. They concluded that PD-L1 expression has a positive, but not statistically significant, impact on OS and recurrence free survival (RFS) of these patients, and that Foxp3 positive T-cells were an independent significant good prognostic factor for both OS and RFS; on the other hand, CD4 T-cells were an independent significant poor prognostic factor for RFS (106).

Since no clinical trials have ever been conducted for LCNEC patients, information related to immunotherapy efficacy only comes from small studies with a few patients treated with checkpoint inhibitors. Three cases of LCNEC managed at the University of Kentucky with immunotherapy were reported by Chauhan et al. (17); all of them were treated with nivolumab after platinum-based chemotherapy progression disease, achieving durable response with a complete radiological response or stable disease. Levra et al. presented their data about ten patients treated with checkpoint inhibitors (nine with nivolumab and one with pembrolizumab); 6/10 achieved partial response and 1/10 showed stable disease with a median PFS of 57 weeks (107). Wang et al. reported a single case of patient with stage IB LCNEC (PD-L1 negative but positive for PD-L1 amplification and tumor mutation burden high) who progressed after adjuvant chemotherapy after surgery; subsequently, the patient was treated with pembrolizumab, and after one cycle, all visible lesions shrunk, and no new lesions were seen. The patient remains on pembrolizumab with continued improvement of the disease 6 months after (108). Similarly, Zhang et al. described a case of a LCNEC patient who rapidly progressed after surgery and adjuvant chemotherapy but achieved complete response during nivolumab treatment probably due to high tumor mutational burden (TMB), although PD-L1 was negative (109). Daido et al. presented two cases of LCNEC treated with nivolumab as third and sixth lines of therapy for rapidly progressing disease to the previous lines; also in this case, the patients reported a radiological response to checkpoint inhibitor therapy (110). Sato et al. (111) reported another case of stage IVB LCNEC without PD-L1 expression that responded to nivolumab as third-line treatment, maybe due to a high $\mathrm{TMB}$ previously reported as predictive of response to 
immunotherapy (108). Agar et al. reported the efficacy of nivolumab in 17 pretreated patients with stage III-IV LCNEC, showing a prolonged $O S$ as second-line treatment or beyond (112).

Although the correlation with response to immune checkpoint inhibitors remains under investigation, all these studies about PD-L1 expression and immunotherapy efficacy in LCNEC are interesting, especially considering the scarcity of treatment options and potential therapeutic targets in this rare and aggressive malignancy. As already mentioned, clinical trials in rare tumors are difficult to conduct; thus available data are not enough to establish immunotherapy role in LCNEC. Prospective data regarding use of immune checkpoint inhibitors are strongly needed (Table 4).

\section{Targeted Therapy}

The identification of molecular aberrations leading to tumor growth and survival has dramatically changed the treatment landscape of NSCLC (113). Despite this complexity, cancer cell growth and survival can often be impaired by the inactivation of a single oncogene, so-called 'driver mutation'. These mutations confer a growth advantage to the cells and have been positively selected during the cancer evolution. This phenomenon, called oncogene addiction, provides a rationale for molecular targeted therapy, that to date represents the gold standard treatment for 'oncogene-addicted' NSCLC (113). Unfortunately, driver mutations are extremely rare in 'pure' LCNEC while they occur more frequently in mixed forms of LCNEC-adenocarcinoma. Nevertheless, some cases of metastatic LCNEC carrying driver mutations (especially EGFR alterations) are reported, showing tyrosine kinase inhibitor (TKI) efficacy (114-116). The first report of LCNEC carrying an EGFR activating mutation and of gefitinib activity in LCNEC patients was published in July 2010; a 66-year-old woman who had never smoked was diagnosed with metastatic LCNEC. An exon 19 deletion of EGFR was detected, and a correlation between exon 19 deletion and LCNEC response to gefitinib was reported (21). Another case harboring an EGFR mutation showed a response to an EGFR-TKI in a LCNEC patient harboring an EGFR gene mutation responded for eight months to the EGFR-TKI icotinib (116). On the contrary, the histological transformation of EGFR-mutated NSCLC in LCNEC could represent a potential mechanism of resistance to TKI treatment (117).

Another driver alteration usually found in young and nonsmoker NSCLC patients is anaplastic lymphoma kinase (ALK)translocation (118), for which several TKIs have been developed and have dramatically changed prognosis of patients carrying this molecular rearrangement $(119,120)$. A few cases are described of LCNEC harboring ALK-translocation with conflicting TKI efficacy $(23,121)$.

With regard to other targets, anti-c-KIT, anti-VEGF, and anti-HER2 agents could be interesting new drugs for LCNEC treatment. Indeed, high expression rates of VEGF were found in LCNEC, supporting further assessment of anti-VEGF therapies in these patients. Likewise, strong expression of HER2 and c-KIT in a subset of patients suggests possible roles for targeted therapies, such as trastuzumab and imatinib, but clinical trials have never been performed and additional analyses are warranted (122).

As already mentioned, alterations in PI3K/AKT/mTOR pathway have been found in LCNEC, in particular PIK3CA mutations, PTEN loss, PIK3CA CNV, and RICTOR CNV (42, 44 ), but no compounds have been developed to target these potential driver alterations in LCNEC patients.

Also for DLL3, an inhibitory Notch-ligand highly expressed in SCLC and LCNEC, targeted therapy could represent a valid tool to improve LCNEC prognosis. Rovalpituzumab tesirine is a first-in-class antibody-drug conjugate directed against DLL3; its activity has been assessed in a phase I study including SCLC and LCNEC pretreated patients, showing an ORR of $18 \%$ and a manageable safety profile (123). In another study, Odate et al. (124) found that the expression of tropomyosin-related kinase B (TrkB) and brain derived neurotrophic factor (BDNF) was significantly higher in LCNEC than in SCLC, and they proposed that these two genes might be potential targets in LCNEC. Rossi et al. (72) conducted a study to achieve more accurate insight on the prognostic and possibly therapeutic value of the KIT receptors (RTKs), Platelet-derived growth factor receptor (PDGFR) $\alpha$, PDGFR $\beta$, and mesenchymal epithelial transition factor (Met). Among these RTKs, only Met was significantly associated with patient survival at univariate analysis, but this data was not confirmed at multivariate analysis.

TABLE 4 | Immunotherapy data in LCNEC patients.

\begin{tabular}{|c|c|c|c|c|c|}
\hline Authors & Type of Study & $\begin{array}{c}\text { Number of } \\
\text { LCNEC patients }\end{array}$ & $\begin{array}{l}\text { Line of } \\
\text { therapy }\end{array}$ & Treatment & Outcomes \\
\hline Wang et al. & Case report & 1 & 1 & Pembrolizumab & $\mathrm{PR}$ \\
\hline Zhang et al. & Case report & 1 & 1 & Nivolumab & $\mathrm{CR}$ \\
\hline Chauhan et al. & Case series & 3 & 2 & Nivolumab & DCR $100 \%$ \\
\hline Levra et al. & Case series & 10 & 2 & Nivolumab $(9 / 10)$ and Pembrolizumab (1/10) & $\begin{array}{c}\text { PR } 60 \% \\
\text { SD 10\% } \\
\text { mPFS } 57 \text { weeks }\end{array}$ \\
\hline Agar et al. & Case series & 17 & $\geq 2$ & Nivolumab & $\begin{array}{c}\text { mOS } 12.1 \text { months } \\
\text { ORR } 29.4 \%\end{array}$ \\
\hline Saito et al. & Case report & 1 & 3 & Nivolumab & PR \\
\hline Daido et al. & Case series & 2 & $3-4$ & Nivolumab & PR \\
\hline
\end{tabular}

DCR, disease control rate; ORR, objective response rate; MPFS, median progression-free survival; CR, complete response; PR, partial response; SD, stable disease. 
Based on these studies, prospective clinical studies on larger series of LCNEC are clearly mandatory to detect potential targetable molecular alterations. Further investigations are needed to develop targeted therapy for these patients.

\section{CONCLUSIONS}

LCNEC is a rare and aggressive tumor. Due to its rarity and its likeness to other neuroendocrine tumors, histological diagnosis can be challenging (16,30-32). Moreover, LCNEC management, especially in the advanced disease, is not clearly established. Physicians tend to treat patients with the same chemotherapyregimens used for SCLC patients, achieving worse results in terms of ORR and OS (12-14). Nevertheless, according to LCNEC subtypes (SCLC-like LCNEC versus NSCLC-like LCNEC), chemotherapy-regimen choice should be driven by their molecular characteristics. Indeed, on the basis of the studies discussed, genomic subtyping represents a valid tool to predict prognosis and detect the best treatment for each LCNEC patient (43). With regard to potential future opportunities, some cases are reported of patients treated with checkpoint inhibitors, often achieving radiological and clinical response, in particular after platinum-based first-line treatment failure (107-111). A few data are also available concerning targeted therapy, due to a low frequency of driver mutations in LCNEC patients, but mostly of them have reported a moderate efficacy of TKIs in this subset of disease $(114,115,119,120)$.

To date, the therapeutic indications are mainly extrapolated from clinical practice, and no prospective clinical trials have been performed for LCNEC patients. Prognosis remains poor, even for early stages compared to NSCLC, regardless of which chemotherapy regimen is used. Therefore, a new paradigm in treating these patients is needed, and the inclusion of LCNEC in

\section{REFERENCES}

1. Travis WD, Rush W, Flieder DB, Falk R, Fleming MV, Gal AA, et al. Survival analysis of 200 pulmonary neuroendocrine tumors with clarification of criteria for atypical carcinoid and its separation from typical carcinoid. Am J Surg Pathol (1998) 22(8):934-44. doi: 10.1097/ 00000478-199808000-00003

2. Iyoda A, Makino T, Koezuka S, Otsuka H, Hata Y. Treatment options for patients with large cell neuroendocrine carcinoma of the lung. In: . General Thoracic and Cardiovascular Surgery, vol. 62. Tokyo: Springer-Verlag (2014). p. 351-6. Available at: pmc/articles/PMC4042022/?report= abstract. doi: 10.1007/s11748-014-0379-9

3. Sun YH, Lin SW, Hsieh CC, Yeh YC, Tu CC, Chen KJ. Treatment outcomes of patients with different subtypes of large cell carcinoma of the lung. Ann Thorac Surg (2014) 98(3):1013-9. doi: 10.1016/j.athoracsur.2014.05.012

4. Travis WD, Brambilla E, Nicholson AG, Yatabe Y, Austin JHM, Beasley MB, et al. The 2015 World Health Organization Classification of Lung Tumors: Impact of Genetic, Clinical and Radiologic Advances since the 2004 Classification. J Thorac Oncol (2015) 10:1243-60. doi: 10.1097/ JTO.0000000000000630

5. Marchevsky AM, Gal AA, Shah S, Koss MN. Morphometry confirms the presence of considerable nuclear size overlap between "small cells" and "large cells" in high-grade pulmonary neuroendocrine neoplasms. Am J Clin Pathol (2001) 116(4):466-72. doi: 10.1309/H40B-8W14-4Q47-03EP clinical trials is strongly recommended to identify the best therapeutic approach and to correlate biomolecular characteristics with the potential role of new treatment strategies.

\section{AUTHOR CONTRIBUTIONS}

MF, ASt, and EB conceived the original idea of the article, drafting and writing the paper. MS, SP, MMa, and FL revised the scientific content of specific sections of the manuscript and participated in drafting specific sections of the paper. EV, MC, AC, and ED'A participated in the critical revision of the paper. MS, SP, MMa, FL, $\mathrm{RT}, \mathrm{GR}, \mathrm{ASc}, \mathrm{SM}$, and MMi participated in the critical revision and editing of the manuscript. GT and EB conceived the original idea and provided critical revision of the manuscript as well as the final approval of the version to publish. All authors contributed to the article and approved the submitted version.

\section{FUNDING}

Institutional funds of Università Cattolica del Sacro Cuore (UCSC).

\section{ACKNOWLEDGMENTS}

EB is currently supported by the Associazione Italiana per la Ricerca sul Cancro (AIRC) under Investigator Grant (IG) No. IG20583. GT is supported by AIRC, IG18599, AIRC $5 \times 1,000$ 21052. EB is currently supported by the Institutional funds of Università Cattolica del Sacro Cuore (UCSC-project D12018-2020).

6. den Bakker MA, Willemsen S, Grünberg K, Noorduijn LA, van Oosterhout MFM, van Suylen RJ, et al. Small cell carcinoma of the lung and large cell neuroendocrine carcinoma interobserver variability. Histopathology (2010) 56(3):356-63. doi: 10.1111/j.1365-2559.2010.03486.x

7. Iyoda A, Hiroshima K, Toyozaki T, Haga Y, Fujisawa T, Ohwada H. Clinical characterization of pulmonary large cell neuroendocrine carcinoma and large cell carcinoma with neuroendocrine morphology. Cancer (2001) 91 (11):1992-2000. doi: 10.1002/1097-0142(20010601)91:11<1992::AIDCNCR1224>3.0.CO;2-5

8. Asamura H, Kameya T, Matsuno Y, Noguchi M, Tada H, Ishikawa Y, et al. Neuroendocrine neoplasms of the lung: A prognostic spectrum. J Clin Oncol (2006) 24(1):70-6. doi: 10.1200/JCO.2005.04.1202

9. Takei H, Asamura H, Maeshima A, Suzuki K, Kondo H, Niki T, et al. Large cell neuroendocrine carcinoma of the lung: A clinicopathologic study of eighty-seven cases. J Thorac Cardiovasc Surg (2002) 124(2):285-92. doi: $10.1067 / \mathrm{mtc} .2002 .122523$

10. Iyoda A, Hiroshima K, Moriya Y, Iwadate Y, Takiguchi Y, Uno T, et al. Postoperative recurrence and the role of adjuvant chemotherapy in patients with pulmonary large-cell neuroendocrine carcinoma. J Thorac Cardiovasc Surg (2009) 138(2):446-53. doi: 10.1016/j.jtcvs.2008.12.037

11. Iyoda A, Jiang S-X, Travis WD, Kurouzu N, Ogawa F, Amano H, et al. Clinicopathological features and the impact of the new TNM classification of malignant tumors in patients with pulmonary large cell neuroendocrine carcinoma. Mol Clin Oncol (2013) 1(3):437-43. doi: 10.3892/mco.2013.80 
12. Masters GA, Temin S, Azzoli CG, Giaccone G, Baker S, Brahmer JR, et al. Systemic therapy for stage IV non-small-cell lung cancer: American society of clinical oncology clinical practice guideline update. J Clin Oncol Am Soc Clin Oncol (2015) 33:3488-515. doi: 10.1200/JCO.2015.62.1342

13. Fasano M, della Corte CM, Papaccio F, Ciardiello F, Morgillo F. Pulmonary large-cell neuroendocrine carcinoma from epidemiology to therapy. J Thorac Oncol (2015) 10:1133-41. doi: 10.1097/JTO.0000000000000589

14. Naidoo J, Santos-Zabala ML, Iyriboz T, Woo KM, Sima CS, Fiore JJ, et al. Large Cell Neuroendocrine Carcinoma of the Lung: Clinico-Pathologic Features, Treatment, and Outcomes. Clin Lung Cancer (2016) 17(5):e1219. doi: 10.1016/j.cllc.2016.01.003

15. Derks JL, Leblay N, Thunnissen E, van Suylen RJ, den Bakker M, Groen HJM, et al. Molecular subtypes of pulmonary large-cell neuroendocrine carcinoma predict chemotherapy treatment outcome. Clin Cancer Res (2018) 24(1):33-42. doi: 10.1158/1078-0432.CCR-17-1921

16. Hung YP. Neuroendocrine Tumors of the Lung: Updates and Diagnostic Pitfalls. Surg Pathol Clinics (2019) 12:1055-71. doi: 10.1016/j.path.2019. 08.012

17. Chauhan A, Arnold SM, Kolesar J, Thomas HE, Evers M, Anthony L. Immune checkpoint inhibitors in large cell neuroendocrine carcinoma: Current status. Oncotarget (2018) 9(18):14738-40. doi: 10.18632/ oncotarget. 24553

18. Simbolo M, Barbi S, Fassan M, Mafficini A, Ali G, Vicentini C, et al. Gene Expression Profiling of Lung Atypical Carcinoids and Large Cell Neuroendocrine Carcinomas Identifies Three Transcriptomic Subtypes with Specific Genomic Alterations. J Thorac Oncol (2019) 14(9):1651-61. doi: 10.1016/j.jtho.2019.05.003

19. Fan Y, Ma K, Wang C, Ning J, Hu Y, Dong D, et al. Prognostic value of PDL1 and PD-1 expression in pulmonary neuroendocrine tumors. OncoTargets Ther (2016) 9:6075-82. doi: 10.2147/OTT.S115054

20. Tsuruoka K, Horinouchi H, Goto Y, Kanda S, Fujiwara Y, Nokihara H, et al. PD-L1 expression in neuroendocrine tumors of the lung. Lung Cancer (2017) 108:115-20. doi: 10.1016/j.lungcan.2017.03.006

21. de Pas TM, Giovannini M, Manzotti M, Trifirò G, Toffalorio F, Catania C, et al. Large-cell neuroendocrine carcinoma of the lung harboring EGFR mutation and responding to gefitinib. J Clin Oncol (2011) 29(34):e819-22. doi: 10.1200/JCO.2011.36.2251

22. Aroldi F, Bertocchi P, Meriggi F, Abeni C, Ogliosi C, Rota L, et al. Tyrosine kinase inhibitors in EGFR-mutated large-cell neuroendocrine carcinoma of the lung? A case report. Case Rep Oncol (2014) 7(2):478-83. doi: 10.1159/ 000365413

23. Omachi N, Shimizu S, Kawaguchi T, Tezuka K, Kanazu M, Tamiya A, et al. A case of large-cell neuroendocrine carcinoma harboring an EML4-ALK rearrangement with resistance to the ALK inhibitor crizotinib. J Thorac Oncol (2014) 9(6):e40-2. doi: 10.1097/JTO.0000000000000103

24. Karlsson A, Brunnström H, Lindquist KE, Jirström K, Jönsson M, Rosengren F, et al. Mutational and gene fusion analyses of primary large cell and large cell neuroendocrine lung cancer. Oncotarget (2015) 6(26):22028-37. doi: 10.18632/oncotarget.4314

25. Rekhtman N, Pietanza MC, Hellmann MD, Naidoo J, Arora A, Won H, et al. Next-generation sequencing of pulmonary large cell neuroendocrine carcinoma reveals small cell carcinoma-like and non-small cell carcinomalike subsets. Clin Cancer Res (2016) 22(14):3618-29. doi: 10.1158/10780432.CCR-15-2946

26. George J, Lim JS, Jang SJ, Cun Y, Ozretia L, Kong G, et al. Comprehensive genomic profiles of small cell lung cancer. Nature (2015) 524(7563):47-53. doi: 10.1038/nature14664

27. Rudin CM, Durinck S, Stawiski EW, Poirier JT, Modrusan Z, Shames DS, et al. Comprehensive genomic analysis identifies SOX2 as a frequently amplified gene in small-cell lung cancer. Nat Genet (2012) 44(10):1111-6. doi: $10.1038 /$ ng. 2405

28. Baine MK, Rekhtman N. Multiple faces of pulmonary large cell neuroendocrine carcinoma: update with a focus on practical approach to diagnosis. Trans Lung Cancer Res (2020) 9(3):860-78. doi: 10.21037/tlcr.2020.02.13

29. Hiroshima K, Mino-Kenudson M. Update on large cell neuroendocrine carcinoma. Trans Lung Cancer Res (2017) 6:530-9. doi: 10.21037/tlcr. 2017.06.12
30. Travis WD, Linnoila RI, Tsokos MG, Hitchcock CL, Cutler GB, Nieman L, et al. Neuroendocrine tumors of the lung with proposed criteria for large-cell neuroendocrine carcinoma: An ultrastructural, immunohistochemical, and flow cytometric study of 35 cases. Am J Surg Pathol (1991) 15(6):529-53. doi: 10.1097/00000478-199106000-00003

31. WD Travis, E Brambilla, HK Müller-Hermelink, CC Harris eds. Pathology \& Genetics of Tumours of the Lung, Pleura, Thymus and Heart IARC/Press (2004) Vol. 344.

32. Thunnissen E, Borczuk AC, Flieder DB, Witte B, Beasley MB, Chung JH, et al. The Use of Immunohistochemistry Improves the Diagnosis of Small Cell Lung Cancer and Its Differential Diagnosis. An International Reproducibility Study in a Demanding Set of Cases. J Thorac Oncol (2017) 12(2):334-46. doi: 10.1016/j.jtho.2017.03.003

33. le Loarer F, Watson S, Pierron G, de Montpreville VT, Ballet S, Firmin N, et al. SMARCA4 inactivation defines a group of undifferentiated thoracic malignancies transcriptionally related to BAF-deficient sarcomas. Nat Genet (2015) 47(10):1200-5. doi: 10.1038/ng.3399

34. Sauter JL, Graham RP, Larsen BT, Jenkins SM, Roden AC, Boland JM. SMARCA4-deficient thoracic sarcoma: A distinctive clinicopathological entity with undifferentiated rhabdoid morphology and aggressive behavior. Mod Pathol (2017) 30(10):1422-32. doi: 10.1038/modpathol.2017.61

35. Yoshida A, Kobayashi E, Kubo T, Kodaira M, Motoi T, Motoi N, et al. Clinicopathological and molecular characterization of SMARCA4-deficient thoracic sarcomas with comparison to potentially related entities. Mod Pathol (2017) 30(6):797-809. doi: 10.1038/modpathol.2017.11

36. Rekhtman N, Montecalvo J, Chang JC, Alex D, Ptashkin RN, Ai N, et al. SMARCA4-Deficient Thoracic Sarcomatoid Tumors Represent Primarily Smoking-Related Undifferentiated Carcinomas Rather Than Primary Thoracic Sarcomas. J Thorac Oncol (2020) 15(2):231-47. doi: 10.1016/ j.jtho.2019.10.023

37. George J, Walter V, Peifer M, Alexandrov LB, Seidel D, Leenders F, et al. Integrative genomic profiling of large-cell neuroendocrine carcinomas reveals distinct subtypes of high-grade neuroendocrine lung tumors. Nat Commun (2018) 9(1):1048. doi: 10.1038/s41467-018-03099-x

38. Deng SM, Yan XC, Liang L, Wang L, Liu Y, Duan JL, et al. The Notch ligand delta-like 3 promotes tumor growth and inhibits Notch signaling in lung cancer cells in mice. Biochem Biophys Res Commun (2017) 483(1):488-94. doi: 10.1016/j.bbrc.2016.12.117

39. Chapman G, Sparrow DB, Kremmer E, Dunwoodie SL. Notch inhibition by the ligand Delta-Like 3 defines the mechanism of abnormal vertebral segmentation in spondylocostal dysostosis. Hum Mol Genet (2011) 20 (5):905-16. doi: $10.1093 / \mathrm{hmg} / \mathrm{ddq} 529$

40. Hermans BCM, Derks JL, Thunnissen E, van Suylen RJ, den Bakker MA, Groen HJM, et al. DLL3 expression in large cell neuroendocrine carcinoma (LCNEC) and association with molecular subtypes and neuroendocrine profile. Lung Cancer (2019) 138:102-8. doi: 10.1016/j.lungcan.2019.10.010

41. Pelosi G, Bianchi F, Dama E, Simbolo M, Mafficini A, Sonzogni A, et al. Most high-grade neuroendocrine tumours of the lung are likely to secondarily develop from pre-existing carcinoids: innovative findings skipping the current pathogenesis paradigm. Virchows Archiv (2018) 472(4):567-77. doi: $10.1007 / \mathrm{s} 00428-018-2307-3$

42. Simbolo M, Mafficini A, Sikora KO, Fassan M, Barbi S, Corbo V, et al. Lung neuroendocrine tumours: deep sequencing of the four World Health Organization histotypes reveals chromatin-remodelling genes as major players and a prognostic role for TERT, RB1, MEN1 and KMT2D. J Pathol (2017) 241(4):488-500. doi: 10.1002/path.4853

43. Zhuo M, Guan Y, Yang X, Hong L, Wang Y, Li Z, et al. The prognostic and therapeutic role of genomic subtyping by sequencing tumor or cell-free DNA in pulmonary large-cell neuroendocrine carcinoma. Clin Cancer Res (2020) 26(4):892-901. doi: 10.1158/1078-0432.CCR-19-0556

44. Miyoshi T, Umemura S, Matsumura Y, Mimaki S, Tada S, Makinoshima H, et al. Genomic profiling of large-cell neuroendocrine carcinoma of the lung. Clin Cancer Res (2017) 23(3):757-65. doi: 10.1158/1078-0432.CCR-16-0355

45. Pelosi G, Pasini F, Fraggetta F, Pastorino U, Iannucci A, Maisonneuve P, et al. Independent value of fascin immunoreactivity for predicting lymph node metastases in typical and atypical pulmonary carcinoids. Lung Cancer (2003) 42(2):203-13. doi: 10.1016/S0169-5002(03)00294-0 
46. Pelosi G, Scarpa A, Puppa G, Veronesi G, Spaggiari L, Pasini F, et al. Alteration of the E-cadherin/ $\beta$-catenin cell adhesion system is common in pulmonary neuroendocrine tumors and is an independent predictor of lymph node metastasis in atypical carcinoids. Cancer (2005) 103(6):115464. doi: 10.1002/cncr.20901

47. Pelosi G, Scarpa A, Veronesi G, Spaggiari L, del Curto B, Moore PS, et al. A subset of high-grade pulmonary neuroendocrine carcinomas shows upregulation of matrix metalloproteinase-7 associated with nuclear $\beta$-catenin immunoreactivity, independent of EGFR and HER-2 gene amplification or expression. Virchows Archiv (2005) 447(6):969-77. doi: 10.1007/s00428005-0044-X

48. Li F, Ye B, Hong L, Xu H, Fishbein MC. Epigenetic modifications of histone H4 in lung neuroendocrine tumors. Appl Immunohistochem Mol Morphol (2011) 19(5):389-94. doi: 10.1097/PAI.0b013e3182108e2e

49. Arbajian E, Aine M, Karlsson A, Vallon-Christersson J, Brunnström H, Davidsson J, et al. Methylation patterns and chromatin accessibility in neuroendocrine lung cancer. Cancers (2020) 12(8):1-17. doi: 10.3390/ cancers 12082003

50. Fournel L, Falcoz PE, Alifano M, Charpentier MC, Boudaya MS, Magdeleinat $\mathrm{P}$, et al. Surgical management of pulmonary large cell neuroendocrine carcinomas: a 10-year experience. Eur J cardio-thorac surgery: Off J Eur Assoc Cardio-thorac Surg (2013) 43(1):111-4. doi: 10.1093/ejcts/ezs174

51. Sakurai H, Asamura H. Large-Cell Neuroendocrine Carcinoma of the Lung: Surgical Management. Thorac Surg Clinics (2014) 24:305-11. doi: 10.1016/ j.thorsurg.2014.05.001

52. Postmus PE, Kerr KM, Oudkerk M, Senan S, Waller DA, Vansteenkiste J, et al. Early and locally advanced non-small-cell lung cancer (NSCLC): ESMO Clinical Practice Guidelines for diagnosis, treatment and follow-up. Ann Oncol (2017) 28:iv1-21. doi: 10.1093/annonc/mdx222

53. Cao L, Li ZW, Wang M, Zhang TT, Bao B, Liu YP. Clinicopathological characteristics, treatment and survival of pulmonary large cell neuroendocrine carcinoma: A SEER population-based study. PeerJ (2019) 7:e6539. doi: 10.7717/peerj.6539

54. Wakeam E, Adibfar A, Stokes S, Leighl NB, Giuliani ME, Varghese TK, et al. Defining the role of adjuvant therapy for early-stage large cell neuroendocrine carcinoma. J Thorac Cardiovasc Surg (2020) 159(5):20432054.e9. doi: 10.1016/j.jtcvs.2019.09.077

55. Gu J, Gong D, Wang Y, Chi B, Zhang J, Hu S, et al. The demographic and treatment options for patients with large cell neuroendocrine carcinoma of the lung. Cancer Med (2019) 8(6):2979-93. doi: 10.1002/cam4.2188

56. Girelli L, Casiraghi M, Sandri A, Petrella F, Galetta D, Gasparri R, et al. Results of Surgical Resection of Locally Advanced Pulmonary Neuroendocrine Tumors. Ann Thorac Surg (2020) S0003-4975(20):31821X. doi: 10.1016/j.athoracsur.2020.09.021

57. Lowczak A, Kolasinska-Cwikla A, Ćwikła JB, Osowiecka K, Palucki J, Rzepko R, et al. Outcomes of Patients with Clinical Stage I-IIIA Large-Cell Neuroendocrine Lung Cancer Treated with Resection. J Clin Med (2020) 9 (5):1370. doi: 10.3390/jcm9051370

58. Zacharias J, Nicholson AG, Ladas GP, Goldstraw P. Large cell neuroendocrine carcinoma and large cell carcinomas with neuroendocrine morphology of the lung: Prognosis after complete resection and systematic nodal dissection. Ann Thorac Surg (2003) 75(2):348-52. doi: 10.1016/S00034975(02)04118-8

59. Eichhorn F, Dienemann H, Muley T, Warth A, Hoffmann H. Predictors of survival after operation among patients with large cell neuroendocrine carcinoma of the lung. Ann Thorac Surg (2015) 99(3):983-9. doi: 10.1016/ j.athoracsur.2014.10.015

60. Raman V, Jawitz OK, Yang CFJ, Voigt SL, Tong BC, D'Amico TA, et al. Outcomes for Surgery in Large Cell Lung Neuroendocrine Cancer. J Thorac Oncol (2019) 14(12):2143-51. doi: 10.1016/j.jtho.2019.09.005

61. Lo H, Abel S, Finley G, Weksler B, Colonias A, Wegner RE. Surgical resection versus stereotactic body radiation therapy in early stage bronchopulmonary large cell neuroendocrine carcinoma. Thorac Cancer (2020) 11(2):305-10. doi: 10.1111/1759-7714.13260

62. Wegner RE, Abel S, Colonias A. Stereotactic ablative body radiotherapy versus conventionally fractionated radiotherapy for early stage large cell neuroendocrine carcinoma of the lung. Lung Cancer Manage (2020) 9(3): LMT32. doi: 10.2217/lmt-2020-0004

63. Raman V, Jawitz OK, Yang CFJ, Tong BC, D’Amico TA, Berry MF, et al. Adjuvant Therapy for Patients With Early Large Cell Lung Neuroendocrine Cancer: A National Analysis. Ann Thorac Surg (2019) 108(2):377-83. doi: 10.1016/j.athoracsur.2019.03.053

64. Jiang Y, Lei C, Zhang X, Cui Y, Che K, Shen H. Double-edged role of radiotherapy in patients with pulmonary large-cell neuroendocrine carcinoma. J Cancer (2019) 10(25):6422-30. doi: 10.7150/jca.32446

65. le Pechoux C, Pourel N, Barlesi F, Faivre-Finn C, Lerouge D, Zalcman G, et al. LBA3_PR An international randomized trial, comparing post-operative conformal radiotherapy (PORT) to no PORT, in patients with completely resected non-small cell lung cancer (NSCLC) and mediastinal N2 involvement: Primary end-point analysis of LungART (IFCT-0503, UK NCRI, SAKK) NCT00410683. Ann Oncol (2020) 31:S1178. doi: 10.1016/ j.annonc.2020.08.2280

66. Iyoda A, Hiroshima K, Moriya Y, Sekine Y, Shibuya K, Iizasa T, et al. Prognostic impact of large cell neuroendocrine histology in patients with pathologic stage Ia pulmonary non-small cell carcinoma. J Thorac Cardiovasc Surg (2006) 132(2):312-5. doi: 10.1016/j.jtcvs.2006.02.046

67. Iyoda A, Hiroshima K, Moriya Y, Takiguchi Y, Sekine Y, Shibuya K, et al. Prospective Study of Adjuvant Chemotherapy for Pulmonary Large Cell Neuroendocrine Carcinoma. Ann Thorac Surg (2006) 82(5):1802-7. doi: 10.1016/j.athoracsur.2006.05.109

68. Kenmotsu H, Niho S, Ito T, Ishikawa Y, Noguchi M, Tada H, et al. A pilot study of adjuvant chemotherapy with irinotecan and cisplatin for completely resected high-grade pulmonary neuroendocrine carcinoma (large cell neuroendocrine carcinoma and small cell lung cancer). Lung Cancer (2014) 84(3):254-8. doi: 10.1016/j.lungcan.2014.03.007

69. Kenmotsu H, Niho S, Tsuboi M, Wakabayashi M, Ishii G, Nakagawa K, et al. Randomized Phase III Study of Irinotecan Plus Cisplatin Versus Etoposide Plus Cisplatin for Completely Resected High-Grade Neuroendocrine Carcinoma of the Lung: JCOG1205/1206. J Clin Oncol (2020) 38(36): JCO.20.01806. doi: 10.1200/JCO.20.01806

70. Kujtan L, Muthukumar V, Kennedy KF, Davis JR, Masood A, Subramanian J. The Role of Systemic Therapy in the Management of Stage I Large Cell Neuroendocrine Carcinoma of the Lung. J Thorac Oncol (2018) 13(5):70714. doi: $10.1016 /$ j.jtho.2018.01.019

71. Veronesi G, Morandi U, Alloisio M, Terzi A, Cardillo G, Filosso P, et al. Large cell neuroendocrine carcinoma of the lung: A retrospective analysis of 144 surgical cases. Lung Cancer (2006) 53(1):111-5. doi: 10.1016/j.lungcan.2006.03.007

72. Rossi G, Cavazza A, Marchioni A, Longo L, Migaldi M, Sartori G, et al. Role of chemotherapy and the receptor tyrosine kinases KIT, PDGFR $\alpha, \operatorname{PDGFR} \beta$, and Met in large-cell neuroendocrine carcinoma of the lung. J Clin Oncol (2005) 23(34):8774-85. doi: 10.1200/JCO.2005.02.8233

73. Sarkaria IS, Iyoda A, Roh MS, Sica G, Kuk D, Sima CS, et al. Neoadjuvant and adjuvant chemotherapy in resected pulmonary large cell neuroendocrine carcinomas: A single institution experience. Ann Thorac Surg (2011) 92(4):1180-7. doi: 10.1016/j.athoracsur.2011.05.027

74. Limonnik V, Abel S, Finley GG, Long GS, Wegner RE. Factors associated with treatment receipt and overall survival for patients with locally advanced large cell neuroendocrine carcinoma of the lung: A National Cancer Database analysis. Lung Cancer (2020) Dec 1150:107-13. doi: 10.1016/ j.lungcan.2020.10.001

75. Shimada Y, Niho S, Ishii G, Hishida T, Yoshida J, Nishimura M, et al. Clinical features of unresectable high-grade lung neuroendocrine carcinoma diagnosed using biopsy specimens. Lung Cancer (2012) 75(3):368-73. doi: 10.1016/j.lungcan.2011.08.012

76. Yamazaki S, Sekine I, Matsuno Y, Takei H, Yamamoto N, Kunitoh H, et al. Clinical responses of large cell neuroendocrine carcinoma of the lung to cisplatin-based chemotherapy. Lung Cancer (2005) 49(2):217-23. doi: 10.1016/j.lungcan.2005.01.008

77. Glisson BS, Moran CA. Large-cell neuroendocrine carcinoma: Controversies in diagnosis and treatment. JNCCN J Natl Compr Cancer Netw (2011) 9:1122-9. doi: 10.6004/jnccn.2011.0093

78. Sun JM, Ahn MJ, Ahn JS, Um SW, Kim H, Kim HK, et al. Chemotherapy for pulmonary large cell neuroendocrine carcinoma: Similar to that for small 
cell lung cancer or non-small cell lung cancer? Lung Cancer (2012) 77 (2):365-70. doi: 10.1016/j.lungcan.2012.04.009

79. le Treut J, Sault MC, Lena H, Souquet PJ, Vergnenegre A, le Caer H, et al. Multicentre phase II study of cisplatin-etoposide chemotherapy for advanced large-cell neuroendocrine lung carcinoma: The GFPC 0302 study. Ann Oncol (2013) 24(6):1548-52. doi: 10.1093/annonc/mdt009

80. Igawa S, Watanabe R, Ito I, Murakami H, Takahashi T, Nakamura Y, et al. Comparison of chemotherapy for unresectable pulmonary high-grade nonsmall cell neuroendocrine carcinoma and small-cell lung cancer. Lung Cancer (2010) 68(3):438-45. doi: 10.1016/j.lungcan.2009.07.003

81. Fujiwara Y, Sekine I, Tsuta K, Ohe Y, Kunitoh H, Yamamoto N, et al. Effect of platinum combined with irinotecan or paclitaxel against large cell neuroendocrine carcinoma of the lung. Japanese J Clin Oncol (2007) 37 (7):482-6. doi: 10.1093/jjco/hym053

82. Niho S, Kenmotsu H, Sekine I, Ishii G, Ishikawa Y, Noguchi M, et al. Combination chemotherapy with irinotecan and cisplatin for large-cell neuroendocrine carcinoma of the lung: A multicenter phase II study. J Thorac Oncol (2013) 8(7):980-4. doi: 10.1097/JTO.0b013e31828f6989

83. Tokito T, Kenmotsu H, Watanabe R, Ito I, Shukuya T, Ono A, et al. Comparison of chemotherapeutic efficacy between LCNEC diagnosed using large specimens and possible LCNEC diagnosed using small biopsy specimens. Int J Clin Oncol (2014) 19(1):63-7. doi: 10.1007/s10147-012-0509-2

84. Travis WD, Brambilla E, Noguchi M, Nicholson AG, Geisinger KR, Yatabe $\mathrm{Y}$, et al. International association for the study of lung cancer/American Thoracic Society/European Respiratory Society international multidisciplinary classification of lung adenocarcinoma. J Thorac Oncol (2011) 6(2):244-85. doi: 10.1097/JTO.0b013e318206a221

85. Monica V, Scagliotti GV, Ceppi P, Righi L, Cambieri A, lo Iacono M, et al. Differential thymidylate synthase expression in different variants of large-cell carcinoma of the lung. Clin Cancer Res (2009) 15(24):7547-52. doi: 10.1158/ 1078-0432.CCR-09-1641

86. Jalal S, Ansari R, Govindan R, Bhatia S, Bruetman D, Fisher W, et al. Pemetrexed in second line and beyond small cell lung cancer: A hoosier oncology group phase II study. J Thorac Oncol (2009) 4(1):93-6. doi: 10.1097/JTO.0b013e31818dele6

87. Christopoulos P, Engel-Riedel W, Grohé C, Kropf-Sanchen C, von Pawel J, Gütz S, et al. Everolimus with paclitaxel and carboplatin as first-line treatment for metastatic large-cell neuroendocrine lung carcinoma: A multicenter phase II trial. Ann Oncol (2017) 28(8):1898-902. doi: 10.1093/ annonc/mdx268

88. Derks JL, van Suylen RJ, Thunnissen E, den Bakker MA, Groen HJ, Smit EF, et al. Chemotherapy for pulmonary large cell neuroendocrine carcinomas: Does the regimen matter? Eur Respir J (2017) 49(6):1601838. doi: 10.1183/ 13993003.01838-2016

89. Kenmotsu Y, Oshita F, Sugiura M, Murakami S, Kondo T, Saito H, et al. Nedaplatin and Irinotecan in Patients with Large-cell Neuroendocrine Carcinoma of the Lung. Anticancer Res (2012) 32(4):1453-6.

90. Miura Y, Kaira K, Sakurai R, Sunaga N, Saito R, Hisada T, et al. High expression of topoisomerase-II predicts favorable clinical outcomes in patients with relapsed small cell lung cancers receiving amrubicin. Lung Cancer (2018) 115:42-8. doi: 10.1016/j.lungcan.2017.11.010

91. Yoshida H, Sekine I, Tsuta K, Horinouchi H, Nokihara H, Yamamoto N, et al. Amrubicin monotherapy for patients with previously treated advanced large-cell neuroendocrine carcinoma of the lung. Japanese J Clin Oncol (2011) 41(7):897-901. doi: 10.1093/jjco/hyr065

92. Ekeblad S, Sundin A, Janson ET, Welin S, Granberg D, Kindmark H, et al. Temozolomide as monotherapy is effective in treatment of advanced malignant neuroendocrine tumors. Clin Cancer Res (2007) 13(10):298691. doi: 10.1158/1078-0432.CCR-06-2053

93. Wei J, Dong XF, Hu ZL, Tang S, Lu YF. Successful treatment with temozolomide in an elderly woman with advanced pulmonary large-cell neuroendocrine carcinoma: A case report. Med (United States) (2018) 97 (51):e13318. doi: 10.1097/MD.0000000000013318

94. Galvano A, Peri M, Guarini AA, Castiglia M, Grassadonia A, de Tursi M, et al. Analysis of systemic inflammatory biomarkers in neuroendocrine carcinomas of the lung: prognostic and predictive significance of NLR, LDH, ALI, and LIPI score. Ther Adv Med Oncol (2020) 12:1-11. doi: 10.1177/ 1758835920942378
95. Reck M, Rodríguez-Abreu D, Robinson AG, Hui R, Csoszi T, Fülöp A, et al. Updated analysis of KEYNOTE-024: Pembrolizumab versus platinum-based chemotherapy for advanced non-small-cell lung cancer with PD-L1 tumor proportion score of 50\% or greater. J Clin Oncol (2019) 37(7):537-46. doi: 10.1200/JCO.18.00149

96. Horn L, Mansfield AS, Szczęsna A, Havel L, Krzakowski M, Hochmair MJ, et al. First-Line Atezolizumab plus Chemotherapy in Extensive-Stage SmallCell Lung Cancer. New Engl J Med (2018) 379(23):2220-9. doi: 10.1056/ NEJMoa1809064

97. Paz-Ares L, Dvorkin M, Chen Y, Reinmuth N, Hotta K, Trukhin D, et al. Durvalumab plus platinum-etoposide versus platinum-etoposide in firstline treatment of extensive-stage small-cell lung cancer (CASPIAN): a randomised, controlled, open-label, phase 3 trial. Lancet (2019) 394 (10212):1929-39. doi: 10.1016/S0140-6736(19)32222-6

98. Calles A, Liao X, Sholl LM, Rodig SJ, Freeman GJ, Butaney M, et al. Expression of PD-1 and Its Ligands, PD-L1 and PD-L2, in Smokers and Never Smokers with KRAS-Mutant Lung Cancer. J Thorac Oncol (2015) 10(12):1726-35. doi: $10.1097 /$ JTO.0000000000000687

99. Dong H, Strome SE, Salomao DR, Tamura H, Hirano F, Flies DB, et al. Tumor-associated B7-H1 promotes T-cell apoptosis: A potential mechanism of immune evasion. Nat Med (2002) 8(8):793-800. doi: 10.1038/nm730

100. Abdel Karim N, Sendilnathan A, Eldessouki I, Orr-Asman M, Xie C, Wang J, et al. PS06.06 Immune Checkpoint Markers in Lung Large Cell Neuroendocrine Carcinomas (L- LCNEC). J Thorac Oncol (2017) 12(11): S1583-4. doi: 10.1016/j.jtho.2017.09.087

101. Kim HS, Lee JH, Nam SJ, Ock CY, Moon JW, Yoo CW, et al. Association of PD-L1 Expression with Tumor-Infiltrating Immune Cells and Mutation Burden in High-Grade Neuroendocrine Carcinoma of the Lung. $J$ Thorac Oncol (2018) 13(5):636-48. doi: 10.1016/j.jtho.2018.01.008

102. Eichhorn F, Harms A, Warth A, Muley T, Winter H, Eichhorn ME. PD-L1 expression in large cell neuroendocrine carcinoma of the lung. Lung Cancer (2018) 118:76-82. doi: 10.1016/j.lungcan.2018.02.003

103. Hermans BCM, Derks JL, Thunnissen E, van Suylen RJ, den Bakker MA, Groen HJM, et al. Prevalence and prognostic value of PD-L1 expression in molecular subtypes of metastatic large cell neuroendocrine carcinoma (LCNEC). Lung Cancer (2019) 130:179-86. doi: 10.1016/j.lungcan.2019.02.022

104. Inamura K, Yokouchi Y, Kobayashi M, Ninomiya H, Sakakibara R, Nishio M, et al. Relationship of tumor PD-L1 (CD274) expression with lower mortality in lung high-grade neuroendocrine tumor. Cancer Med (2017) 6 (10):2347-56. doi: 10.1002/cam4.1172

105. Arpin D, Charpentier MC, Bernardi M, Monnet I, Boni A, Watkin E, et al. PD-L1-expression patterns in large-cell neuroendocrine carcinoma of the lung: potential implications for use of immunotherapy in these patients: the GFPC 03-2017 "EPNEC" study. Ther Adv Med Oncol (2020) 12:1-8. doi: $10.1177 / 1758835920937972$

106. Ohtaki Y, Kaira K, Atsumi J, Nagashima T, Kawashima O, Ibe T, et al. Prognostic significance of PD-L1 expression and tumor infiltrating lymphocytes in large cell neuroendocrine carcinoma of lung. Am J Trans Res (2018) 10(10):3243-53.

107. Levra MG, Mazieres J, Valette CA, Molinier O, Planchard D, Frappat V, et al. P1.07-012 Efficacy of Immune Checkpoint Inhibitors in Large Cell Neuroendocrine Lung Cancer: Results from a French Retrospective Cohort. J Thorac Oncol (2017) 12(1):S702-3. doi: 10.1016/j.jtho.2016.11.923

108. Wang VE, Urisman A, Albacker L, Ali S, Miller V, Aggarwal R, et al. Checkpoint inhibitor is active against large cell neuroendocrine carcinoma with high tumor mutation burden. J ImmunoTher Cancer (2017) 5(1):75. doi: 10.1186/s40425-017-0281-y

109. Zhang X, Sun Y, Miao Y, Xu S. Immune checkpoint inhibitor therapy achieved complete response for drug-sensitive egfr/alk mutation-negative metastatic pulmonary large-cell neuroendocrine carcinoma with high tumor mutation burden: A case report. OncoTargets Ther (2020) 13:8245-50. doi: 10.2147/OTT.S259893

110. Daido W, Yamasaki M, Saito N, Ishiyama S, Deguchi N, Taniwaki M, et al. Effectiveness of nivolumab in large-cell neuroendocrine carcinoma of the lung A report of two cases. Japanese J Cancer Chemother (2017) 44(1):59-62.

111. Sato MT, Ikezawa Y, Sato M, Suzuki A, Kawai Y. Large cell neuroendocrine carcinoma of the lung that responded to nivolumab: A case report. Mol Clin Oncol (2020) 13(1):43-7. doi: 10.3892/mco.2020.2045 
112. Agar C, Geier M, Léveiller G, Lamy R, Bizec J-L, Tiercin M, et al. Brief report on efficacy of nivolumab in patients with previously treated advanced largecell neuroendocrine cancer of the lung. JTO Clin Res Rep (2020) 2(4):100129. doi: 10.1016/j.jtocrr.2020.100129

113. Ferrara MG, di Noia V, D’argento E, Vita E, Damiano P, Cannella A, et al. Oncogene-addicted non-small-cell lung cancer: Treatment opportunities and future perspectives. Cancers (2020) 12:MDPI AG. doi: 10.3390/ cancers12051196

114. Yoshida Y, Ota S, Murakawa T, Takai D, Nakajima J. Combined large cell neuroendocrine carcinoma and adenocarcinoma with epidermal growth factor receptor mutation in a female patient who never smoked. Ann Thorac Cardiovasc Surg (2014) 20:582-4. doi: 10.5761/atcs.cr.12.02217

115. Yanagisawa S, Morikawa N, Kimura Y, Nagano Y, Murakami K, Tabata T. Large-cell neuroendocrine carcinoma with epidermal growth factor receptor mutation: Possible transformation of lung adenocarcinoma. Respirology. Respirology (2012) 17:1275-7. doi: 10.1111/j.1440-1843.2012.02258.x

116. Wang Y, Shen YH, Ma S, Zhou J. A marked response to icotinib in a patient with large cell neuroendocrine carcinoma harboring an EGFR mutation: A case report. Oncol Lett (2015) 10(3):1575-8. doi: 10.3892/ol.2015.3405

117. Kogo M, Shimizu R, Uehara K, Takahashi Y, Kokubo M, Imai Y, et al. Transformation to large cell neuroendocrine carcinoma as acquired resistance mechanism of EGFR tyrosine kinase inhibitor. Lung Cancer (2015) 90(2):364-8. doi: 10.1016/j.lungcan.2015.09.002

118. Shaw AT, Yeap BY, Mino-Kenudson M, Digumarthy SR, Costa DB, Heist RS, et al. Clinical features and outcome of patients with non-small-cell lung cancer who harbor EML4-ALK. J Clin Oncol (2009) 27(26):4247-53. doi: 10.1200/JCO.2009.22.6993

119. Solomon BJ, Mok T, Kim D-W, Wu Y-L, Nakagawa K, Mekhail T, et al. FirstLine Crizotinib versus Chemotherapy in ALK -Positive Lung Cancer. New Engl J Med (2014) 371(23):2167-77. doi: 10.1056/NEJMoa1408440

120. Peters S, Camidge DR, Shaw AT, Gadgeel S, Ahn JS, Kim D-W, et al. Alectinib versus Crizotinib in Untreated ALK -Positive Non-Small-Cell
Lung Cancer. New Engl J Med (2017) 377(9):829-38. doi: 10.1056/ NEJMoa1704795

121. Hayashi N, Fujita A, Saikai T, Takabatake H, Sotoshiro M, Sekine K, et al. Large cell neuroendocrine carcinoma harboring an anaplastic lymphoma kinase (ALK) rearrangement with response to alectinib. Internal Med (2018) 57(5):713-6. doi: 10.2169/internalmedicine.9368-17

122. Iyoda A, Travis WD, Sarkaria IS, Jiang SX, Amano H, Sato Y, et al. Expression profiling and identification of potential molecular targets for therapy in pulmonary large-cell neuroendocrine carcinoma. Exp Ther Med (2011) 2(6):1041-5. doi: 10.3892/etm.2011.343

123. Rudin CM, Pietanza MC, Bauer TM, Ready N, Morgensztern D, Glisson BS, et al. Rovalpituzumab tesirine, a DLL3-targeted antibody-drug conjugate, in recurrent small-cell lung cancer: a first-in-human, first-in-class, open-label, phase 1 study. Lancet Oncol (2017) 18(1):42-51. doi: 10.1016/S1470-2045 (16)30565-4

124. Odate S, Nakamura K, Onishi H, Kojima M, Uchiyama A, Nakano K, et al. TrkB/BDNF signaling pathway is a potential therapeutic target for pulmonary large cell neuroendocrine carcinoma. Lung Cancer (2013) 79 (3):205-14. doi: 10.1016/j.lungcan.2012.12.004

Conflict of Interest: The authors declare that the research was conducted in the absence of any commercial or financial relationships that could be construed as a potential conflict of interest.

Copyright (c) 2021 Ferrara, Stefani, Simbolo, Pilotto, Martini, Lococo, Vita, Chiappetta, Cancellieri, D’Argento, Trisolini, Rindi, Scarpa, Margaritora, Milella, Tortora and Bria. This is an open-access article distributed under the terms of the Creative Commons Attribution License (CC BY). The use, distribution or reproduction in other forums is permitted, provided the original author(s) and the copyright owner(s) are credited and that the original publication in this journal is cited, in accordance with accepted academic practice. No use, distribution or reproduction is permitted which does not comply with these terms. 